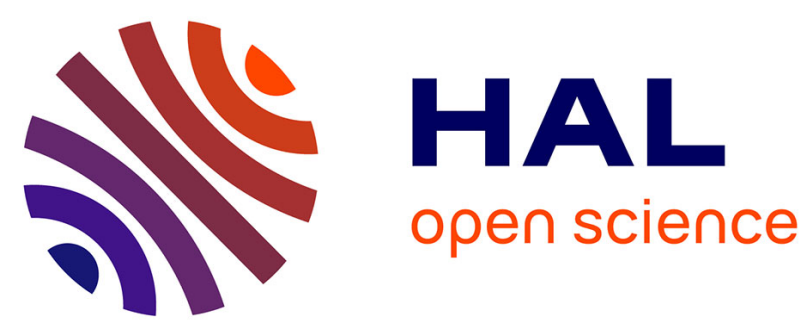

\title{
Relationship between airborne electrical and total water content measurements in ice clouds
}

\author{
Aurélie Bouchard, Philippe Lalande, Pierre Laroche, Patrice Blanchet, \\ Magalie Buguet, Arnaud Chazottes, J. Walter Strapp
}

\section{To cite this version:}

Aurélie Bouchard, Philippe Lalande, Pierre Laroche, Patrice Blanchet, Magalie Buguet, et al.. Relationship between airborne electrical and total water content measurements in ice clouds. Atmospheric Research, 2019, 237, 104836, p. 1-16. 10.1016/j.atmosres.2019.104836 . hal-02456043

\section{HAL Id: hal-02456043 \\ https://hal.science/hal-02456043}

Submitted on 27 Jan 2020

HAL is a multi-disciplinary open access archive for the deposit and dissemination of scientific research documents, whether they are published or not. The documents may come from teaching and research institutions in France or abroad, or from public or private research centers.
L'archive ouverte pluridisciplinaire HAL, est destinée au dépôt et à la diffusion de documents scientifiques de niveau recherche, publiés ou non, émanant des établissements d'enseignement et de recherche français ou étrangers, des laboratoires publics ou privés. 


\section{Relationship between airborne electrical and Total Water Content} measurements in ice clouds.

Authors : Aurélie Bouchard, Philippe Lalande, Pierre Laroche, Patrice Blanchet, Magalie Buguet, Arnaud Chazottes

Affiliation : DPHY, ONERA, Université Paris Saclay, F-92322 Châtillon - France

Co-authorship: J. Walter Strapp, Met Analytics Inc.

\section{Abstract}

During the High Altitude Ice Crystal -High Ice Water Content (HAIC-HIWC) project, instrumented aircraft were flown in the vicinity and inside deep tropical convective clouds. Among the probes installed on one of these aircraft, were the Isokinetic Probe (IKP2), to retrieve the cloud total water content (TWC) and the AMPERA (Atmospheric Measurement of Potential and Electric field on Aircraft) system to provide information on the electrostatic state of the atmosphere and the aircraft.

AMPERA is an electric field mill network which locally measures the electrostatic field at the aircraft fuselage. The distribution and amplitude of the electrostatic field on the aircraft skin depends on the atmospheric electrostatic field around the aircraft and the net electric charge of the aircraft. This latter parameter depends on the balance between the triboelectric current due to the impact of the cloud particles on the aircraft fuselage, the current due to the charged particles emitted by the engines, and the corona current emitted by the aircraft.

Based on the flights of the HAIC-HIWC campaigns, which were conducted almost exclusively in cloud composed of ice particles, a comparison between the total water content recorded by microphysical sensor and the aircraft net charge has highlighted the possibility of deducing an estimate of the TWC from the aircraft electrical potential. In contrast to conventional TWC probes which sample a local area of the atmosphere, the AMPERA system uses the aircraft as a sensor and provides an overall estimation of its net TWC exposure. This study provides the first results of the efficacy of the electrostatic method through comparisons with direct in-situ bulk TWC measurements in ice clouds.

\section{Introduction}

Since the 1990s, jet aircraft engine power-loss and damage events have been linked to exposures to high ice particle mass concentrations in convective clouds (Lawson et al. 1998, Mason et al. 2006, Flegel, 2018). Such conditions have also been recognized to adversely affect the measurements of air data probes. Engine studies have shown that ice crystals entering the propulsion system's flow path can alter the thermodynamics and result in internal ice accretion, sometimes resulting in surge, flame-out, or rollback (Mason et al. 2006). Shedding of accreted ice can damage engine internal components. Engine events have usually occurred in conditions that appear benign to pilots, including light-moderate turbulence, low on board weather radar reflectivity, only occasional lightning, and the absence of airframe icing. The typical event is at relatively high altitude and 
warmer than a standard atmosphere. These types of icing conditions are mostly outside the longstanding Title 14 Code of Federal Regulations, Part 25 Appendix C conventional cloud icing certification envelope. In the early 2000s, an Aviation Rulemaking Advisory Committee was formed to study mixed/phase glaciated icing with the intention of updating icing certification standards if appropriate. The efforts led to the definition of new standards for icing certification in Supercooled Large Droplet (SLD) and high ice water content (IWC) conditions, the latter of which led to the new Title 14 Code of Federal Regulations Part 33 Appendix D (FAA) icing envelope at its EASA CS-25 Appendix $P$ equivalent (hereafter Appendix $D / P$ ). The task of defining the engine problem, and forming a technical plan for advancing knowledge of the poorly understood ice crystal icing phenomenon was assigned to the Engine Harmonization Working Group (EHWG), an association of industry, government and regulatory icing experts.

Appendix $\mathrm{D} / \mathrm{P}$ was developed based on a combination of theoretical calculations and in-situ measurements taken during the 1950s (Mazzawy and Strapp, 2007). The EHWG agreed that there were limited cloud measurements to corroborate the Appendix, and recommended new in-situ measurements of the types of clouds that caused engine events for assessment. In anticipation of these regulation changes, the European High Altitude Ice Crystals (HAIC; Dezitter, 2013) and North American High Ice Water Content (HIWC; Strapp et al. 2016) projects formed the international HAICHIWC collaboration to make new in-situ measurements with modern instrumentation and techniques. The HAIC-HIWC project performed two measurement campaigns, one in Darwin Australia in 2014, and a second in Cayenne, French Guiana in 2015. Additional independent measurements were made by HIWC in Florida in 2015, and by HAIC in Darwin and Reunion Island in $2016^{1}$. The projects aimed to characterize microphysical parameters near convective cores of deep tropical convective clouds, using common idealized flight plans described by Strapp et al. (2016). The data have been analyzed and compared to Appendix D/P (Strapp et al. 2019), and will be used in future ARAC (Aviation Rulemaking Advisory Committee) discussions assessing the suitability of Appendix D/P.

Most HAIC-HIWC measurements (around 92\%) were made within mesoscale convective systems of oceanic origin (Strapp et al. 2019), targeting suspected regions of high Ice Water Content (IWC). In order to simulate commercial aircraft high IWC exposures, transects across the entire cloud width were made if possible, passing close to or through convective updraft regions using conventional safe distances employed by pilots if required. Although there has been no common definition used by the HAIC-HIWC research team of a high IWC region, Leroy et al. (2017) used a threshold of $1.5 \mathrm{gm}^{-3}$ in their study of ice particle size distributions (PSDs) observed during the HAIC-HIWC flights. Yost et al. 2018 used a nominal threshold of $1 \mathrm{gm}^{-3}$ in their study of satellite detection of high IWC regions. Overall characteristics of the Darwin-2014, Cayenne-2015, and Florida-2015 flight campaign clouds have been summarized by Strapp et al. (2019). In this study, only the Darwin and Cayenne campaign data are discussed, because the combination of instruments of primary interest were installed only for these two projects. The data collection aircraft was the Service des Avions Français Instrumentés pour la Recherche en Environnement (SAFIRE) Dassault Falcon 20. Although common flight plans were used, the campaigns differ somewhat in the temperatures at which data were collected. The Darwin campaign was successful in collecting data at the primary flight levels of $-30^{\circ} \mathrm{C}$ and $-40^{\circ} \mathrm{C}(10-$

\footnotetext{
${ }^{1}$ The HAIC project included a focus on, and additional independent flights for the detection of high IWC conditions using new innovative instrumentation concepts.
} 
$11 \mathrm{~km} \mathrm{AMSL}$ ), but collected limited data at the other primary levels of $-10^{\circ} \mathrm{C}$ and $-50^{\circ} \mathrm{C}$, partially due to the early termination of the flight campaign. The Cayenne flight campaign collected data at all 4 primary flight levels, but specifically targeted the $-10^{\circ} \mathrm{C}$ and $-50^{\circ} \mathrm{C}$ levels in order to collect the data missed in Darwin. Both campaigns targeted oceanic mesoscale-convective systems (MCSs), with the Cayenne campaign also targeting afternoon continental convection.

In both campaigns, the clouds were mostly glaciated, although in Cayenne-2015 a small increase in mixed-phase cloud was observed due to the greater time spent around the $-10 \mathrm{C}$ temperature level. Overall, mixed-phase cloud comprised less than $5 \%$ of the in total in-cloud distance, with narrow mixed-phase events always less than about $6.2 \mathrm{Nm}$ and with event-average liquid water content (LWC) less than about $0.32 \mathrm{gm}^{-3}$. The probability of mixed phase cloud decreased with altitude. Consequently, the comparisons of this article refer almost exclusively to the correlation of the electric field properties to ice water content (IWC), although small amounts of liquid may also be present for short periods, which would also be included in the TWC measurement. Further details on features of the clouds and analyses of the datasets can be found in other HAIC-HIWC articles and reports (e.g. Leroy et al., 2017; Strapp et al. 2019).

One of the goals of the HAIC project was the improvement of methods to detect icing conditions to reduce the risk of aircraft incidents in such weather conditions (Dezitter, 2013). Different techniques have been used to retrieve the LWC and/or IWC and/or TWC based on direct measurement, among them hot wire, flow-through evaporator methodologies, the latter using differential hygrometry (Brenguier et al., 2013; Baumgardner, 2011) and the ice accretion methodology. A number of sensors based of one more of these principles were installed on the SAFIRE Falcon-20 for the HAIC-HIWC campaigns, including the Isokinetic Probe (Davison et al., 2008), the Science Engineering Associates Robust probe (Strapp et al., 2008; Grandin et al., 2014), the Rosemount Icing Rate Sensor (Baumgardner, 2011). Other techniques estimate water content through indirect measurements of the cloud Particle Size Distribution or radar reflectivity. Particle imaging probes, capable of providing an estimate of the IWC through size to mass conversion (Stratton Park Engineering Co. (SPEC) 2DStereo probe (2D-S), Droplet Measurement Technologies (DMT) Precipitation Imaging Probe (PIP), Leroy (2016) and the multi-beam Radar SysTem Airborne (RASTA) 95GhZ Doppler cloud radar providing reflectivity, doppler velocity and an estimation of the IWC as a derived product (Protat et al., 2009; Delanoe et al. , 2013), were also installed on the Falcon 20.

In the framework of the HAIC project, ONERA proposed a new concept for the estimation of the TWC, based on the measurement of the electrostatic field on the aircraft fuselage. During the HAICHIWC campaigns, a network of electrostatic field meters, called AMPERA (Atmospheric Measurement of Potential and Electric Field on Aircraft), was installed on the SAFIRE Falcon 20 aircraft. This system supplies information on the electrostatic state of the atmosphere (Laroche, 2012). The ONERA approach is based on the concept that the aircraft itself can be used as a sensor to provide information on cloud TWC through its correlation to electrostatic charging of the aircraft and the surrounding cloud particles. A charge measurement single sensor developed by the National Research Council (NRC) of Canada has also been tested within HAIC, although not on the Falcon-20. Details can be found in Davison et al. (2018).

For each flight of the HAIC-HIWC campaigns, a wide variety of sensors has been installed on the aircraft to sample the microphysical, dynamical and electrostatic characteristics of the atmosphere. 
In the framework of our study, our interest was focused on microphysical sensors implemented on the same aircraft as the AMPERA system (the Falcon 20 aircraft). Unfortunately, not all data recorded by the different sensors were available. Consequently, in this study, comparisons were restricted between the TWC estimated with the Isokinetic Probe (IKP2) bulk TWC evaporator (Davison et al. 2008, Davidson et al. 2016, Strapp et al. 2016) and the measurements of the AMPERA system.

\section{Airborne estimation of total water content}

2.1 Airborne probes for the retrieval of the total water content on research aircraft

Sensors which are currently used worldwide on research aircraft for the estimation of liquid and ice water content during flight have been reviewed exhaustively elsewhere. Different perspectives can be found in Baumgardner et al. (2011), Brenguier et al. (2013), and Korolev et al. (2017), and only a brief summary relevant to this study will be given here. The measurement of IWC will be emphasized, due to the rarity of mixed-phase measurements in the HAIC-HIWC dataset (section 1).

A first instrument category estimates ice (or liquid) water content based on the integration of the particle size distribution and a size to mass conversion. This method requires knowledge of the effective density variation as a function of the particle size. Uncertainties associated with this method for IWC come from the wide variety of crystal shapes and densities in nature, and fundamental uncertainties in the PSD accuracy, such as depth of field uncertainty and out-of-focus particle sizing corrections (Korolev et al., 1998a; Baumgardner et al., 2011; Abel, 2014; Leroy et al., 2016). Furthermore, accurate separation of liquid and ice particles in mixed-phase situations is a largely un-resolved problem for size less than approximately $100 \mathrm{um}$.

A second category includes the estimation of IWC from combined retrievals of radar reflectivity, the terminal fall speed of hydrometeors and the Particle Size Distribution (Protat, 2016).

A third and more direct technique relies on the measurement of the power used for melting and evaporating ice particles impacting the surface of a heated hot wire sensor. The Nevzorov probe (Korolev et al., 1998b) and the SEA Robust probe (Strapp et al., 2008; Grandin et al., 2014) are based on this principle. One of the main difficulties of these probes for IWC measurement is the relatively low efficiency for capture and evaporation of ice particles, of the order of $30-50 \%$ by some estimates (Strapp et al., 2008; Grandin et al., 2014; Korolev et al., 2013; Leroy et al., 2017), and the lack of comprehensive characterization of this efficiency. Furthermore, the LWC efficiency is typically close to unity, so the deconvolution in mixed-phase conditions requires two sensing wires with differing LWC and IWC efficiencies (Korolev et al., 1998b; Brenguier et al., 2013), and the accuracy of this method has not been evaluated in a wide variety of conditions. A single TWC wire can provide very misleading results in mixed phase conditions due to this LWC vs. TWC efficiency difference.

A fourth category relies on the evaporation of hydrometeors and differential hygrometry. Hydrometeors enter an inlet exposed directly to the air stream. TWC is deduced from the vapour concentration of evaporated hydrometeors, measured by one or more hygrometers. Among the probes based on this technique are the Counterflow Virtual Impactor (CVI: Noone et al., 1993; Twohy et al. 1997), the UK Met Office Total Water probe (Nicholls et al. 1990, Baumgardner et al., 2011; Abel 2014), the Fast In Situ Stratospheric Hygrometer (FISH: Schiller, 2008; Zöger, 1999), and the Isokinetic Probe (IKP2; Davison et al. 2008). One potentially large advantage of this technique is that 
it is possible to obtain near unit efficiency for hydrometeor sampling if the flow is controlled to isokinetic values; however, liquid and solid phase cannot not be differentiated with this technique.

A further technique employed during HAIC-HIWC for the estimation of LWC used the Rosemount Icing rate sensor, which is mainly responsive to only the supercooled water droplets (Baumgardner and Rodi, 1989; Cober et al., 2001; Baumgardner, 2011). The measurement is based on changes in the natural frequency of an oscillating cylinder due to accretion of ice on its surface. Although this technique is open to uncertainties, it can be useful in mixed-phase situations when separating the LWC and IWC components of the PSD is often difficult using other probes.

Table 1 contains a simple and non-exhaustive list of the possible methods for estimating airborne TWC during flights with the SAFIRE Falcon-20. As mentioned before, among listed probes, not all data are available for our investigations, as the Nevzorov, the CVI and the RICE probe.

Table 1 : Summary of methods and sensors used to estimate airborne total water content on the SAFIRE Falcon-20

\begin{tabular}{|c|c|c|c|}
\hline Method & $\begin{array}{l}\text { Sensor basing on the } \\
\text { method }\end{array}$ & Measurement campaign & Reference article \\
\hline $\begin{array}{l}\text { Estimation of the TWC } \\
\text { based on the integration } \\
\text { of the particle size } \\
\text { distribution and the mass } \\
\text { size conversion }\end{array}$ & 2D-S, PIP & $\begin{array}{c}\text { Megha-Tropiques, HAIC- } \\
\text { HIWC, HYMEX }\end{array}$ & $\begin{array}{c}\text { Leroy, 2016; } \\
\text { Baumgardner et al., } \\
\text { 2017; Fontaine, } 2014\end{array}$ \\
\hline \multirow[t]{2}{*}{$\begin{array}{l}\text { Measurement of the } \\
\text { power used for melting } \\
\text { and evaporation of } \\
\text { particles impacting a } \\
\text { heated hot wire sensor }\end{array}$} & SEA Robust & HAIC-HIWC & $\begin{array}{c}\text { Strapp, } 2008 \text {; Leroy, } \\
2017\end{array}$ \\
\hline & Nevzorov & HYMEX & Korolev, 2013 \\
\hline \multirow[t]{2}{*}{ Differential hygrometry } & CVI & POLARCAT & $\begin{array}{c}\text { Noone, 1993; Twohy, } \\
1997\end{array}$ \\
\hline & IKP2 & HAIC-HIWC & $\begin{array}{c}\text { Davidson, 2008; Strapp, } \\
2016\end{array}$ \\
\hline $\begin{array}{l}\text { Estimation of the total } \\
\text { water content from } \\
\text { combined retrievals }\end{array}$ & RASTA & $\begin{array}{l}\text { HYMEX, MEGHA } \\
\text { TROPIQUES }\end{array}$ & Protat 2009, 2016 \\
\hline $\begin{array}{l}\text { Change in the natural } \\
\text { frequency of an } \\
\text { oscillating cylinder (LWC) }\end{array}$ & RICE & HAIC-HIWC & Baumgardner et al., 2011 \\
\hline
\end{tabular}


Table 1 lists the probes that were installed on the SAFIRE Falcon-20 during the HAIC-HIWC campaigns that provided estimates of TWC. During the HAIC-HIWC campaigns, the Isokinetic Evaporator Probe (IKP2) has been chosen as the reference TWC probe. That's why this probe has been chosen to investigate the results supplied by the AMPERA system. The Isokinetic Evaporator Probe was developed by the NRC and Environment Canada specifically for the measurement of the highaltitude, high speed, high IWC environment (up to $20 \mathrm{hPa}, 200 \mathrm{~ms}^{-1},-50^{\circ} \mathrm{C}$, and $10 \mathrm{gm}^{-3}$ ) with a target TWC accuracy of $20 \%$, after the EHWG concluded that instruments existing at the time were either too unreliable or contained uncertainties that could not be sufficiently accurately determined. The development of the original IKP probe has been extensively documented in the literature (Davison et al. 2008, 2009, 2010a, 2010b, 2011). The downsizing effort to the IKP2 probe, required for installation on the Falcon-20, and its extensive wind tunnel testing has been described by Strapp et al. (2016). System accuracy estimates and equations governing the TWC calculation have been provided by Davison et al. (2016). The principle of operation of the IKP and IKP2 probes has been described in the references above, and is repeated briefly here. Cloud particles are ingested in an inlet facing the incoming air stream. The flow through the inlet system is throttled with a butterfly value to approximate the isokinetic value, so that hydrometeors entering the probe have a concentration and distribution, as close as possible to the concentration and distribution present in the free atmosphere. The hydrometeors melt and evaporate inside the probe in a spiral evaporator section. The basic measurement of the probe is then made by sampling the vapour concentration in the flow path after hydrometeor evaporation. Since that measurement includes contributions from both the hydrometeors and the pre-evaporation background water vapour (BWV), a separate measurement of BWV must be made and subtracted from the IKP2 flow path vapour concentration. For HAIC-HIWC, this background measurement was made off the fuselage of the aircraft with an independent rear-facing inlet, intended to sample the humidity of the air without ingesting hydrometeors. Licor-840a hygrometers were used for both the IKP2 and background measurements.

System uncertainty estimates for the IKP2 have been provided by Davison et al. (2016) for three temperature intervals of focus in the HAIC-HIWC flight campaigns. At higher TWCs, uncertainties are of the order of $2-3 \%$. But the subtraction of BWV becomes increasingly important with increasing temperature and decreasing TWC, as saturation BWV levels increase exponentially, and typically exceed $2 \mathrm{~g} \cdot \mathrm{m}^{-3}$ at $-10^{\circ} \mathrm{C}$. Relatively small fractional errors in the BWV levels thus become important, particularly at low TWC values. Consequently, system uncertainty calculations increase to of the order of $50 \%$ at $-10^{\circ} \mathrm{C}$ and $0.1 \mathrm{~g} \cdot \mathrm{m}^{-3}$, and can be further exacerbated by poor synchronization or differing time response of the IKP2 and BWV measurements. For this reason, the use of the IKP2 is practically limited to temperatures colder than about $0^{\circ} \mathrm{C}$ in turbulent tropical atmospheres (Strapp et al. 2016).

During the HAIC-HIWC campaigns, difficulties were experienced measuring BWV due to wetting of the air sampling lines, and ingestion of ice particles that erroneously enhanced the measurement in high TWC conditions. Due to the observation that HAIC-HIWC clouds were mostly glaciated, the decision was made to assume ice saturation concentrations in cloud for all IKP2 TWC calculations. Some errors could be expected from this assumption. The decision received some support from an Environment and Climate Change Canada (ECCC) analysis of in-cloud ice supersaturation measurements on the National Research Council Convair-580 during the only 4 flights with reliable BWV measurements during HAIC-HIWC, which showed that the average BWV concentrations were only slightly supersaturated with respect to ice. By randomly injecting BWV errors implied from the 
above measurements into the HAIC-HIWC dataset, Strapp et al. (2019) first showed that the ice saturation assumption had little effect on the $99^{\text {th }}$ percentile TWC values of most interest to the EHWG. Furthermore, there was almost no effect overall in the $-40^{\circ} \mathrm{C}$ and $-50^{\circ} \mathrm{C}$ temperature intervals due to the very low BWV concentrations. The effects were largest in the warmest $-10^{\circ} \mathrm{C}$ temperature interval, where an overall low-bias was observed for TWCs $<0.6 \mathrm{~g} . \mathrm{m}^{-3}$ (e.g. $20 \%$ at $0.1 \mathrm{gm}^{-3}$ ), and a high bias for TWCs $>0.6 \mathrm{~g} . \mathrm{m}^{-3}$, maximizing at about $6 \%$ at $1.2 \mathrm{~g} . \mathrm{m}^{-3}$. In addition to these average biases however, noise with a standard deviation of approximately $\pm 0.13, \pm 0.07, \pm 0.03$, and \pm 0.004 g. $\mathrm{m}^{-3}$ was added to the IKP2 TWC estimate for the $-10,-30,-40$, and $-50^{\circ} \mathrm{C}$ intervals respectively, roughly independent of TWC. Consequently, the ice saturation BWV assumption is expected to introduce small biases and some scatter, as described above, into the IKP2 TWC and AMPERA comparisons, particularly for the -10 and $-30 \mathrm{C}$ intervals. Scatter is also expected due to the vast differences in the sample volumes being sampled between the IKP2 and AMPERA, which are typically about $10^{-4} \mathrm{~m}^{3} \mathrm{~s}^{-1}$ for the IKP2 versus probably greater than $2.10^{3} \mathrm{~m}^{3} \mathrm{~s}^{-1}$ for exposed particle impact regions on the Falcon-20 which would contribute to the AMPERA measurements.

\section{The AMPERA system}

Since the 1940s, there have been many studies estimating the atmospheric electrostatic field in fair weather conditions, but also in the vicinity and inside thunderstorms. In this framework, different kinds of airborne sensors have been developed. Design of these sensors depends on the airborne platforms that carry the instruments (Mac Gorman and Rust, 1998). These include, for example, the electric field meter (Gun, 1948; Winn, 1993), the rocket borne field meter (Winn and Moore 1971), the airborne rotating vane field mill (Jones, 1990), the cylindrical field mill (Kasemir, 1972; Mac Gorman and Rust, 1998) and the rotating field mill on balloons (Chauzy, 1991; Marshall and Rust 1991; Stolzenburg, 1998). In contrast to the rocket or the balloon, the use of aircraft allows a more comprehensive temporal and spatial analysis of the electrostatic field. Aircraft platforms have provided the only way to measure the horizontal cross-section of a cloud to date (Christian, 1976; Merceret et al., 2008). From this perspective, airborne field mills have been adopted for atmospheric research by ONERA for decades (Laroche, 1986) and tested on different kinds of aircraft (e.g. C160 Transall, Delannoy, 2012; Gloster Meteor NF11, Boulay, 1982; Falcon 20).

An illustration of the field mill used during HAIC-HIWC is shown on the left panel of figure 1. The field mill designed by ONERA differs from other field mills, such as those of Bateman (2007) in that there is an external grid in front of the measurement electrode. As illustrated on figure 1, there are only three sectors in the grid of the ONERA field mills through which the external electrostatic field reaches the measurement electrode. 


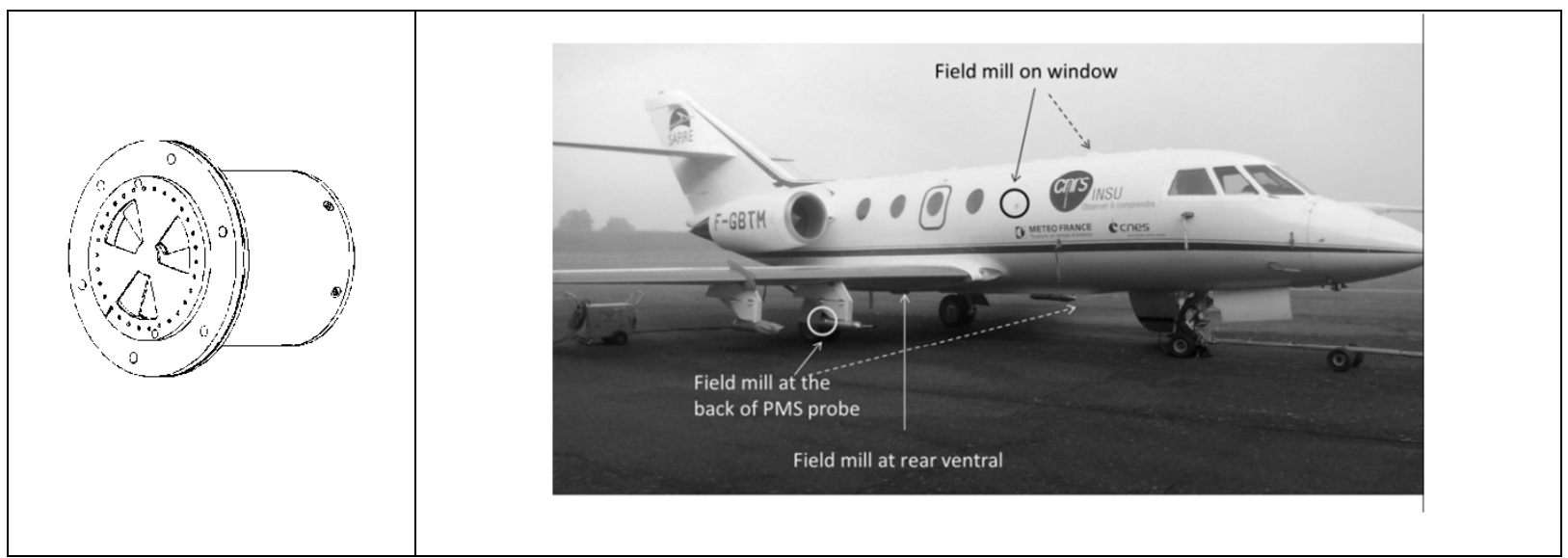

Figure 1: AMPERA system. On the left panel: a picture of the field mill. On the right panel: Illustration of the implementation of the AMPERA system on the Falcon 20 aircraft during the HAIC-HIWC campaigns. The locations of the field mills comprising the AMPERA system are indicated by arrows.

Each rotating-vane field mill measures the electrostatic field at its location on the aircraft. The rotating-vane alternately shields and exposes the sensing plate to the external electric field. The variation of the charge induced on the measurement electrode is tied to the electric field (Bateman, 2007). Each field mill on the aircraft skin continuously records the electrostatic field during flight, which depends on the atmospheric electric field around the aircraft and the net electric charge of the aircraft. The aircraft electrical potential $V_{a}$ is equal to the net charge divided by the aircraft capacitance $\mathrm{C}_{\mathrm{a}}$.

The characteristics and performance of one field mill, determined from laboratory tests, are detailed on table 2. Field mills need to detect both weak electrostatic field as in fair weather (typically, the magnitudes are less than 100 and $20 \mathrm{~V} \cdot \mathrm{m}^{-1}$ near the ground and near $5 \mathrm{~km}$ respectively) and strong electrostatic fields (typically more than $100 \mathrm{kV} \cdot \mathrm{m}^{-1}$ ) inside thunderstorms (MacGorman, 1998). Fair weather measurements are used during the calibration phase. For these reasons, the field mills have a large dynamic range, as indicated in table 2. Furthermore, field mills have been designed to the environment of the aircraft. Most of the time, during the HAIC-HIWC campaigns, the flight envelope was from ground level (ca. $1000 \mathrm{hPa}$ and $26^{\circ} \mathrm{C}$ ) to about $12 \mathrm{~km}$ (ca. $200 \mathrm{hPa},-50^{\circ} \mathrm{C}$ ). These thresholds are consistent with the AMPERA operating environment limits.

Table 2 : Performance and characteristics of each field mill of the AMPERA system

Physical

Mass

Power

Size

\section{$0.870 \mathrm{~kg}$}

28V (DC) ; $25 \mathrm{~W}$ max

$120 \mathrm{~mm} \times 115 \mathrm{~mm}$
Dynamic range

Threshold of detection
Below $5 \mathrm{kV} / \mathrm{m}$

Above $5 \mathrm{kV} / \mathrm{m}$
+/- $5 \mathrm{~V} / \mathrm{m}$ to $+/-1 \mathrm{MV} / \mathrm{m}$

\begin{tabular}{ccc}
\hline Threshold of detection & Below $5 \mathrm{kV} / \mathrm{m}$ & $5 \mathrm{~V} / \mathrm{m}$ \\
\hline Sampling rate & Above $5 \mathrm{kV} / \mathrm{m}$ & $20 \mathrm{~V} / \mathrm{m}$ \\
\hline
\end{tabular}




\begin{tabular}{ccc}
\hline Operating environment & Temperature & $-55^{\circ} \mathrm{C}$ to $60{ }^{\circ} \mathrm{C}$ \\
& Pressure min & $44.4 \mathrm{hPa}(70000 \mathrm{ft})$ \\
& Relative Humidity & $5 \%$ to $100 \%$ \\
& Shock protection & Acceleration peak value $6 \mathrm{G}$ \\
\hline Operating mode & Alimentation and Ethernet \\
& connection \\
\hline
\end{tabular}

\subsection{AMPERA during HAIC-HIWC}

In order to obtain an estimate of the three components of the atmospheric electrostatic field and the aircraft potential, the use of multiple field mills on the same aircraft is required. AMPERA is a field mill network (Laroche, 2012) installed on the fuselage of the aircraft, requiring a minimum of four field mills. Each field mill is flush mounted in order to reduce electrostatic distortion by the aircraft and the sensors. The locations of the field mills have been chosen for symmetry, the sensitivity of the potential dependency, and redundancy of measurement.

Each field mill brings local information of the electrostatic state on the aircraft surface. All data from each field mill of the AMPERA system are synchronized.

During the Darwin-2014 and the Cayenne-2015 campaigns, the AMPERA system consisted of a network of five field mills. These sensors were installed on window blanks at the rear central fuselage and the back of under-wing Particle Measuring System (PMS) probes of the SAFIRE Falcon 20 aircraft. The locations of field mills on the Falcon 20 aircraft, used during both campaigns, are identified on the right panel of figure 1 and in table 3 .

Table 3 : Location of the five field mills of the AMPERA system for the HAIC-HIWC campaign.

\section{Field Mill \\ number \\ Field mill location of the aircraft}

1

2

3

4

5
At the rear central fuselage

On a right window blank

On a left window blank

At the back of the PMS probes - under the starboard wing

At the back of the PMS probes - under the port wing

Each field mill of the AMPERA system continuously measures the local electrostatic field on the aircraft surface during aircraft flight. The estimation of the atmospheric field components and the 
aircraft potential are deduced from the signal recorded by the field mill by applying the calibration method of Winn (1993). Almost all other methodologies used by the research community (Koshak, 1994, 2006) rely on the same principle as that used for AMPERA.

Based on the assumption of a uniform atmospheric electrostatic field around the aircraft (Laroche 1986), a linear relationship can be established between the electrostatic field on the aircraft skin and the three components of the atmospheric electrostatic field and the aircraft potential (Bateman, 2007; Jones, 1990; Laroche, 1986, 2012; Koshak 2006; Mach, 2007, 2015). This relationship can be expressed by:

$$
E_{i}=\alpha_{i} E o x+\beta_{i} E o y+\gamma_{i} E o z+\lambda_{i} V_{a}
$$

where $E_{i}$ is the electrostatic field recording by an individual field mill; $E_{o x}, E_{o y}, E_{o z}$ are the three components of the atmospheric electrostatic field; $V_{a}$ is the aircraft potential; $\alpha_{i}, \beta_{i}, \lambda_{i}, \gamma_{i}$ are constants. Each constant is a function of the form factor of the aircraft and can be inferred by inflight calibration and by numerical computations.

Nowadays, there are two field mill calibration methodologies commonly used by the research community. The first is based on flight calibrations in fair weather, with roll and pitch maneuvers (Koshak, 2006; Mach, 2007; Winn, 1993). The second is based on a numerical calculation using a 3D mesh shape model of the aircraft (Mazur, 1987).

For the HAIC-HIWC project, a Poisson equation solver has been used to numerically compute the value of $E_{i}$ based on the three-dimensional shape model (Figure 2) of the Falcon 20 aircraft for four following configurations detailed in table 4 .

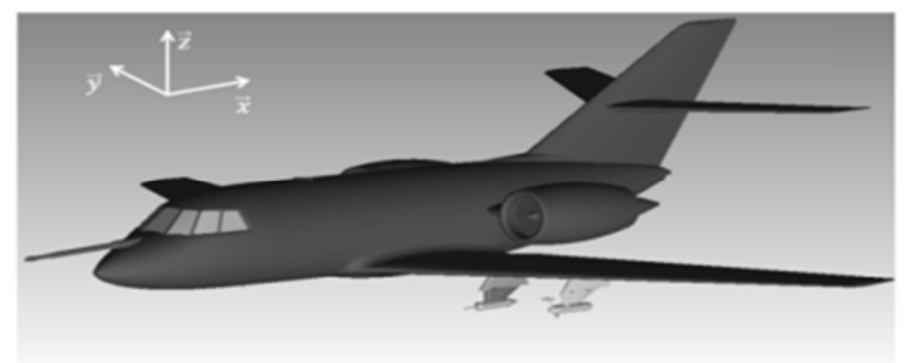

Figure 2 : Three dimensional shape model of the Falcon 20 aircraft.

Table 4: The four configurations used to compute the value of $E_{i}$ on the three dimensional model of the Falcon 20 aircraft.

\begin{tabular}{ccccc}
\hline Configuration & $\mathrm{E}_{\mathrm{ox}}(\mathrm{V} / \mathrm{m})$ & $\mathrm{E}_{\mathrm{oy}}(\mathrm{V} / \mathrm{m})$ & $\mathrm{E}_{\mathrm{oz}}(\mathrm{V} / \mathrm{m})$ & $\mathrm{V}_{\mathrm{a}}(\mathrm{V})$ \\
\hline 1 & 1 & 0 & 0 & 0 \\
2 & 0 & 1 & 0 & 0 \\
3 & 0 & 0 & 1 & 0 \\
4 & 0 & 0 & 0 & 1 \\
\hline
\end{tabular}


Table 5 : The $\mathbf{M}_{\mathrm{ja}}$ Matrix used
321

Results of the four configurations provide estimates of the $\alpha_{i}, \beta_{i}, \lambda_{i}, \gamma_{i}$ coefficients for each field mill location. The values of the $\alpha_{i}, \beta_{i}, \lambda_{i}, \gamma_{i}$ coefficients for each field mill are combined to form the transfer matrix $\mathbf{M}_{\mathrm{ja}}$. The $\mathbf{M}_{\mathrm{ja}}$ matrix obtained for the HAIC-HIWC campaigns is contained in table 5.

\section{$E_{x}$}

MAC 1

MAC 2

MAC 3

MAC 4

MAC 5

\section{1}

2

2

1.1

0.55

\section{$E_{y}$}

0

$-1.4$

1.4

$-2.7$

5

\section{$E_{z}$}

$-1.65$

0.15

0.6

0.2

0.2

0.6

$-4.4$

0.65

The linear equation (1) is applied to the HAIC-HIWC field mill configuration (five field mills as described previously - see figure 1). The five linear equation system can be expressed as the following:

$$
E_{m}=\boldsymbol{M}_{\boldsymbol{j a}} A
$$

where $\mathbf{E}_{\mathrm{m}}$ is an array of measurements recorded by field mills, $\mathbf{M}_{\mathrm{ja}}$ is a transfer matrix, which contains all constant coefficients, and $\mathbf{A}$ is the desired array of the three components of the local electrostatic $\left(E_{o x}, E_{o y}, E_{o z}\right)$ field and the aircraft potential $\left(V_{a}\right)$. The $A$ matrix is found by inverting equation (2), which is least square determination of the matrix A (Laroche, 1986). The A matrix resolved is expressed as the following:

$$
A=\left(M_{j a}{ }^{T} \cdot M_{j a}\right)^{-1} M_{j a}{ }^{T} E_{m}
$$

Mazur (1987) and Mach (2009) have shown that there are different sources of error associated with this methodology.

The accuracy is dependent on two causes: the Mja coefficient matrix which reflects the airplane form factor, i.e. the link between ambient and local field and the measurement of electrostatic on aircraft surface.

The total error on the evaluation of the aircraft potential $V_{a}$ are computed by considering a random error on each measurement $\left(E_{m}\right)$ and on each computed element of the matrix $\mathbf{M}_{\mathrm{ja}}$. Despite a careful sensors calibration in laboratory and on the aircraft, we consider an overall relative error in the measurement of $2 \%$. For the matrix coefficient, $\mathbf{M}_{\mathrm{ja}}$, the considered error was $+/-5 \%$.

The errors on $V_{a}$ depends on the electrical state of the atmosphere $\left(E_{x}, E_{y}\right.$, and $\left.E_{z}\right)$ and the relative magnitude of the aircraft potential. The relative error computation has been calculated with an atmospheric field of $1 \mathrm{~V} / \mathrm{m}$ in the aircraft referential. Each components of the atmospheric electrostatic field are fixed to $1 \mathrm{~V} / \mathrm{m}$. For this state of the atmosphere, the error on the aircraft potential has been estimated for different value of aircraft potential. Results are presented on figure 
3. The figure 3 shows the evolution of the error on $V_{a}$ versus $V_{a}$ magnitude weighted by the norm of the atmospheric electrostatic field.

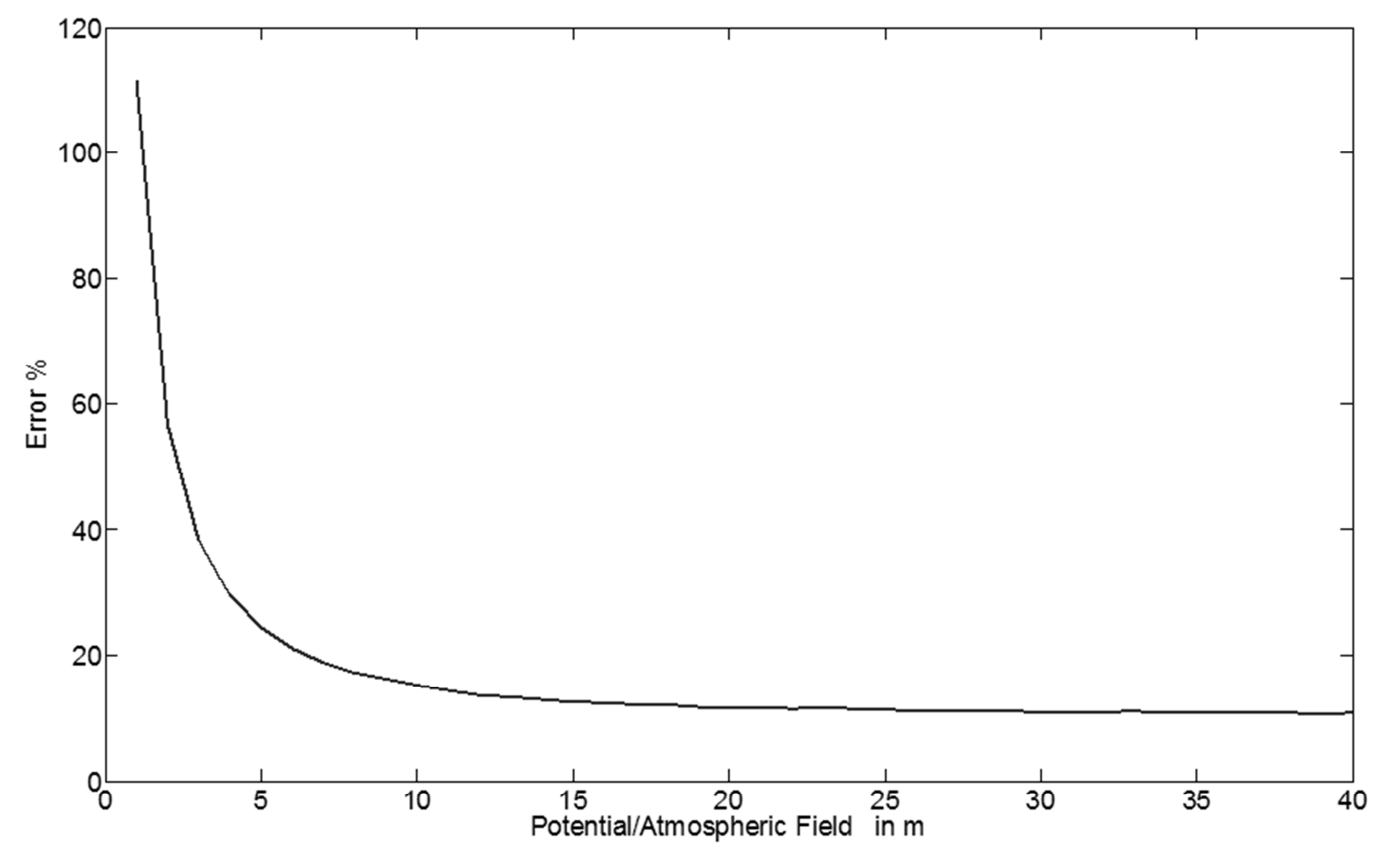

Figure 3 : Relative error on the computation of Va versus the ratio $V_{a} / E_{a}$ for $+/-2 \%$ error on measurement of electric field on the aircraft and $+/-5 \%$ error on computation of matrix $M_{j a}$ elements.

351

352

353

354

When magnitude of the atmospheric field is between 10 and 20 times lower than the magnitude of the aircraft potential, the relative error on the evaluation of the potential range between $+/-15 \%$ and $+/-10 \%$.

For the SAFIRE Falcon-20 in HAIC-HIWC, due to this error, the minimum detectable atmospheric electrostatic field is about $1000 \mathrm{~V} . \mathrm{m}^{-1}$ when the aircraft potential has a magnitude of $100 \mathrm{kV}$.

\subsection{Recording by the AMPERA system}

An example of the methodology and results obtained with the AMPERA system is given on figure 4, for flight FS14019 (02/09/2014) of the Darwin-2014 campaign. The measurements are in ice clouds with no LWC present, initially at a temperature of $-37 \mathrm{C}$, and in the later part of the sequence at -47 C. The take-off and landing times of this flight were 20:48 and 00:14 UTC respectively. The figure contains separate plots for the individual measurements from the five field mills used during the Darwin-2014 campaign, with locations of each numbered field mill detailed in table 3 . The decrease of the electrical field, below $-2000 \mathrm{~V} \cdot \mathrm{m}^{-1}$ is associated with the presence of the cloud. The differences between the measurements are due to the sensitivity of each field mill to the aircraft potential, the atmospheric electrical field and the form factor of the aircraft. The methodology described above is next applied to the data. The time history of the module of the aircraft potential retrieved after the inversion of equation (2) is plotted in figure 5a, with the IKP2 TWC overlaid. The temporal variations between the two parameters are strongly correlated. 


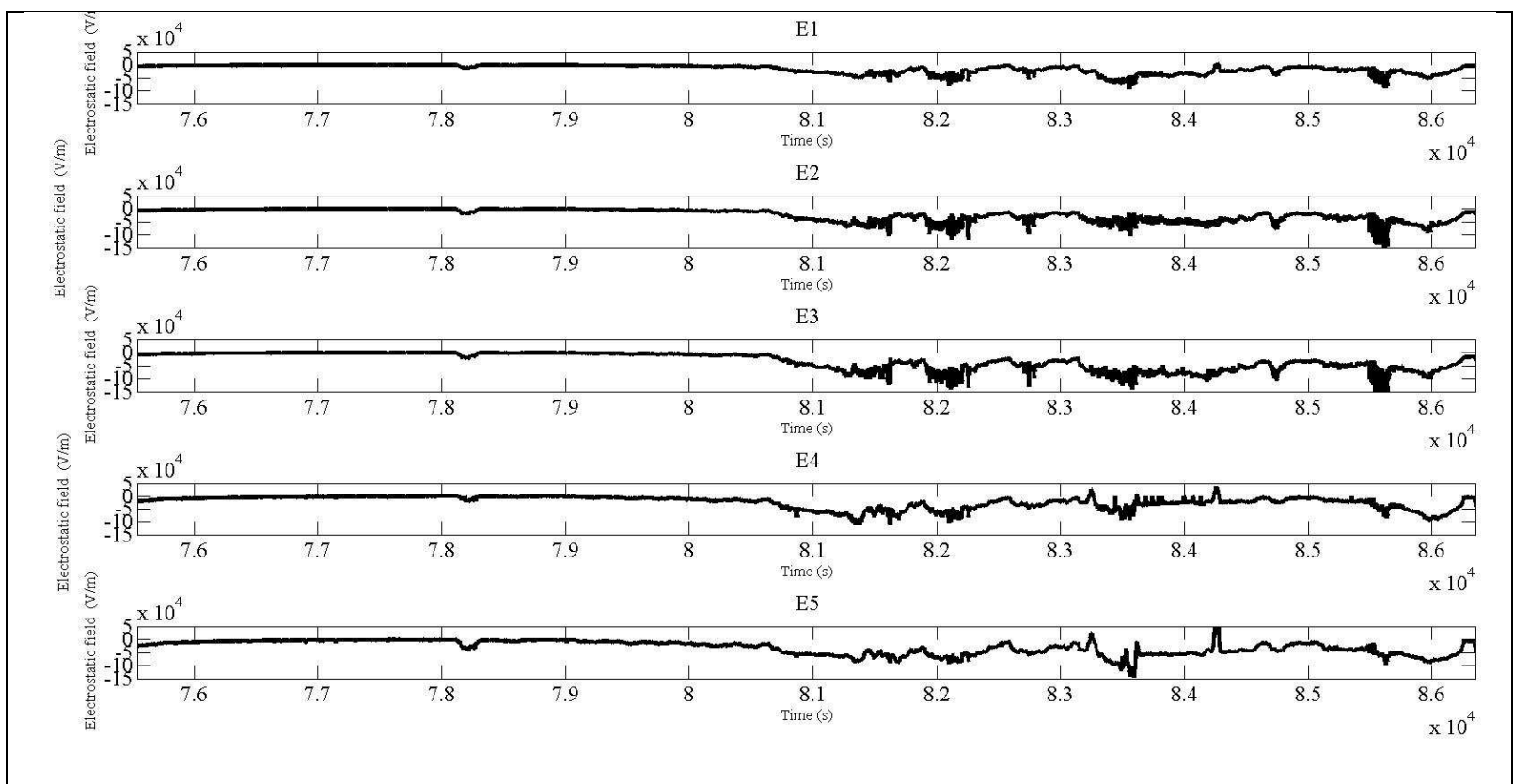

Figure 4 : Measurements from the five field mills of AMPERA system for Flight FS140019 of the Darwin-2014 campaign (2/9/2014). Each curve represents the measurements of one field mill. Plot E1 (first from the top) is for the field mill on the rear fuselage. Plots E2 and E3 (second and third from the top), are for the field mills on the left and right windows, respectively. Plots E4 and E5 (fourth and fifth from the top), respectively E5 (fifth plot for the plot) is for field mill, are for field mills at the back of PMS probes, on the port and starboard side respectively.

At the beginning of the time sequence, the aircraft flies through an isolated cloud at $11 \mathrm{~km} \mathrm{AMSL}$, identified by the letter $A$ on figure $5 \mathrm{a}$. A zoomed illustration of the results for cloud $A$ is included in figures $5 b$ and $5 c$. In figure $5 b$, the recording from the field mill at the back rear fuselage and TWC from IKP2 have been plotted. This field mill has been chosen for its relatively high sensitivity to electrical potential variation. The comparison of TWC and IKP2 data, plotted in figure 5b, highlights the generally good agreement in time evolution when the aircraft flies through an isolated cloud. Previous studies have noted that the electric field on the aircraft, recorded by a field mill, may be dominated by the aircraft potential (Bateman, 2007; Mach, 2007). In figure 5c, the retrieved aircraft potential is plotted with the IKP2 TWC overlaid. Local maxima of TWC are observed at $78160 \mathrm{~s}, 78190$ s, $78200 \mathrm{~s}, 78220 \mathrm{~s}$ and $78260 \mathrm{~s}$. Maxima are found at the same times in the aircraft potential. Moreover, when the TWC is above about $0.1 \mathrm{~g} \cdot \mathrm{m}^{-3}$, a significant variation of aircraft potential is detected.

The aircraft potential sign is linked to the kind of cloud crossed by the plane. It comes from the aircraft charging due to the triboelectric effect. Several authors (Illingworth, 1986; Keith, 1990; Laroche, 1986; Tanner, 1961) reported negative charging of metal target impacted by ice crystal; this observed in laboratory experiment as well as in flight experiment; whereas droplet observed in warm clouds or in mixed-phase region of convective cloud produces a positive charging of the aircraft. In this article, our focus was on the time variation of the module of the aircraft potential but not its sign. 


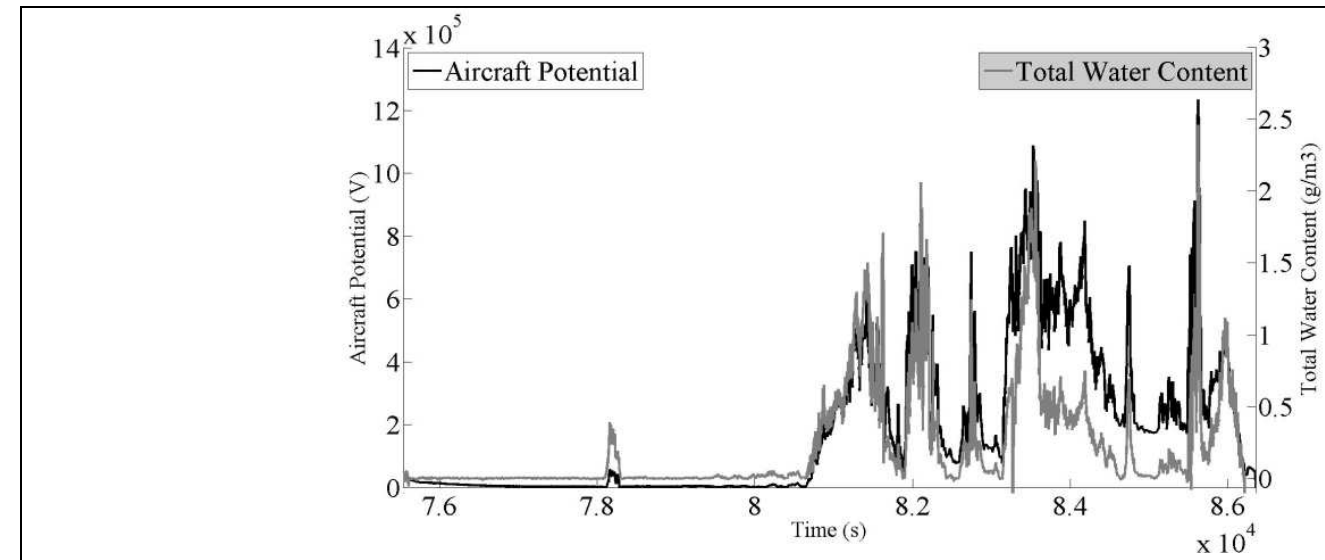

5a: Time history of the norm of the aircraft potential (black curve- units: V) deduced from AMPERA, and TWC (grey curve units: $g . \mathrm{m}^{-3}$ ) from the IKP2 probe.

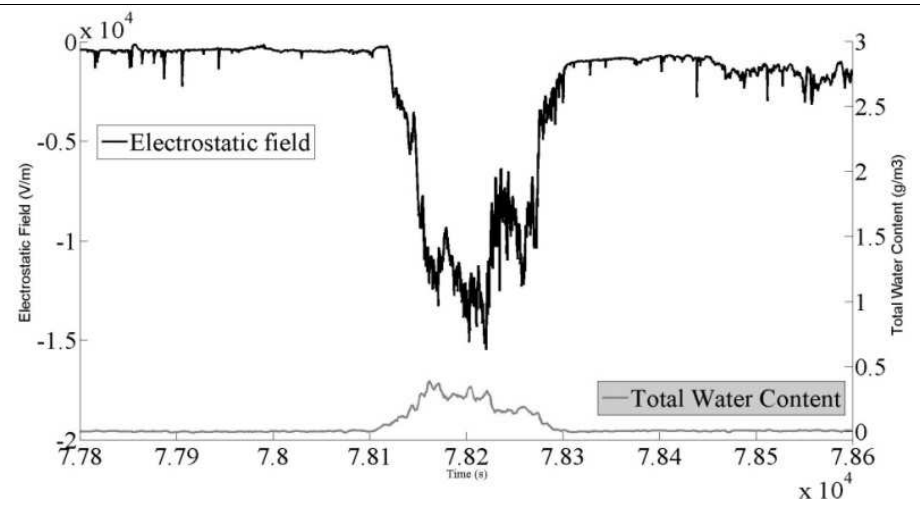

5b: Zoomed time history for cloud A identified in figure 5a. Plots are for the electrostatic field (V.m $\left.{ }^{-1}\right)$ at the rear fuselage (black curve) and the TWC (g. $\mathrm{m}^{-3}$ ) from IKP2 probe (grey curve).

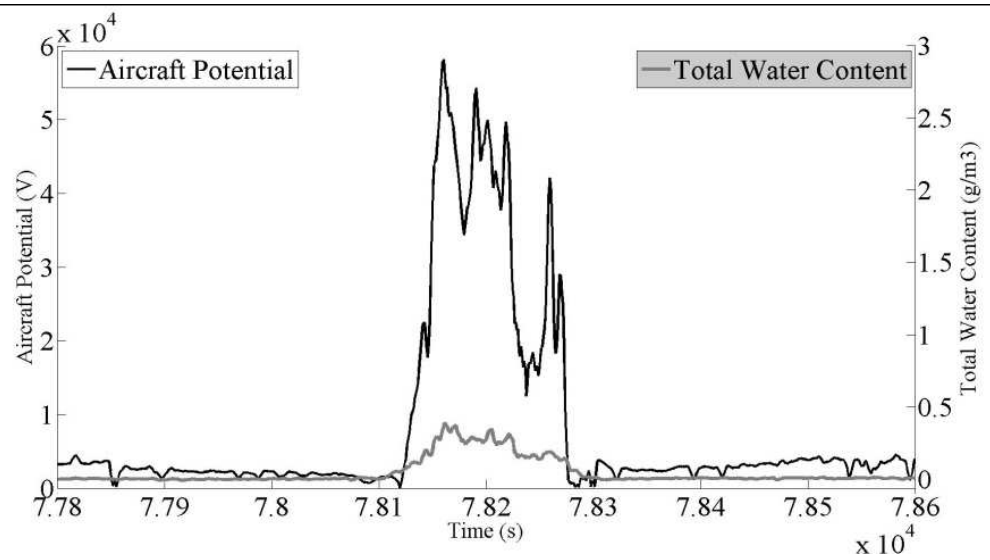

$5 c$ : As in figure $5 b$, but for the norm of the aircraft potential rather than the electrostatic field (black curve). IKP2

Figure 5 : Example of field mill and TWC measurements for flight FS14019 (2/9/2014) of the Darwin-2014 campaign from HAIC-HIWC project. The top panel (figure 5a) contains cloud measurements from the entire flight, including the time evolution of aircraft potential (black curve) in V deduced from the AMPERA system, and the TWC (grey curve) in g. $\mathrm{m}^{-3}$ from IKP2 probe. Time is indicated on $x$-axis in seconds since UTC midnight. Figures $5 b$ and 5 bcontain zoomed field mill and TWC results from cloud $A$ identified in figure $5 \mathrm{a}$. Figure $5 \mathrm{~b}$ contains time histories of the electrostatic field results $(\mathrm{V} / \mathrm{m})$ for the rear back fuselage field mill (black curve), and TWC from the IKP2 (grey curve). Figure $5 c$ is as in figure $5 b$, but for the aircraft potential (V) rather than the electrostatic field (black curve). 


\section{Results}

\subsection{Analysis methodology}

All data from the Darwin-2014 and Cayenne-2015 have been sorted in order to have the same temporal basis for the IKP probe and AMPERA results and to only use relevant data for our study.

In order to calculate the regression coefficient and study the correlation between parameters, common time-averaging has been used. Due to an observed Licor hygrometer high-frequency overshoot/undershoot problem in large step changes, IKP2 data have been provided to the HAICHIWC research team as 5-second centered averages at 1 second spacing. The AMPERA system supplies information on the electrostatic field at a resolution of $100 \mathrm{~ms}$. In order to be consistent with IKP2 time resolution, the same averaging method and scale has been applied to the field mill data.

Furthermore, in order to remove the aircraft potential signature, which will not be relevant for this study, and to take into account the detection limit of the IKP2 probe, data have been sorted based on the following points for each flight of both campaigns:

- Periods when the IKP2 TWC was below $0.1 \mathrm{~g} \cdot \mathrm{m}^{-3}$ have been excluded due to the limitation in the accuracy of the IKP2 probe at low TWC and the warmer temperatures (Davison et al. 2016, Strapp et al. 2016).

- Take-off and landing periods have been excluded. During these times, fluctuations in aircraft potential are dominated by electrostatic charge induced at high power by engine exhaust. This phenomenon is reproducible from one flight to another. An example of the take-off period of flight FS140019 (Darwin-2014) and flight FS150015 (Cayenne-2015) is shown in figure 6 . For both flights, the take off period was in fair weather. None of the microphysical probes detect the presence of TWC. Each plot shows the aircraft potential recorded by the rear field sensor and the TWC measured by the IKP 2 probe during take-off period. Both plots reveal a quick decrease of the aircraft potential, followed by a steady signal increase. This evolution of the aircraft potential is consistent with observations made by Nanevicz (1975). For these cases, no data before 75540s and 59480s have been used in the statistics calculations for flights FS14019 and FS150015 respectively. 


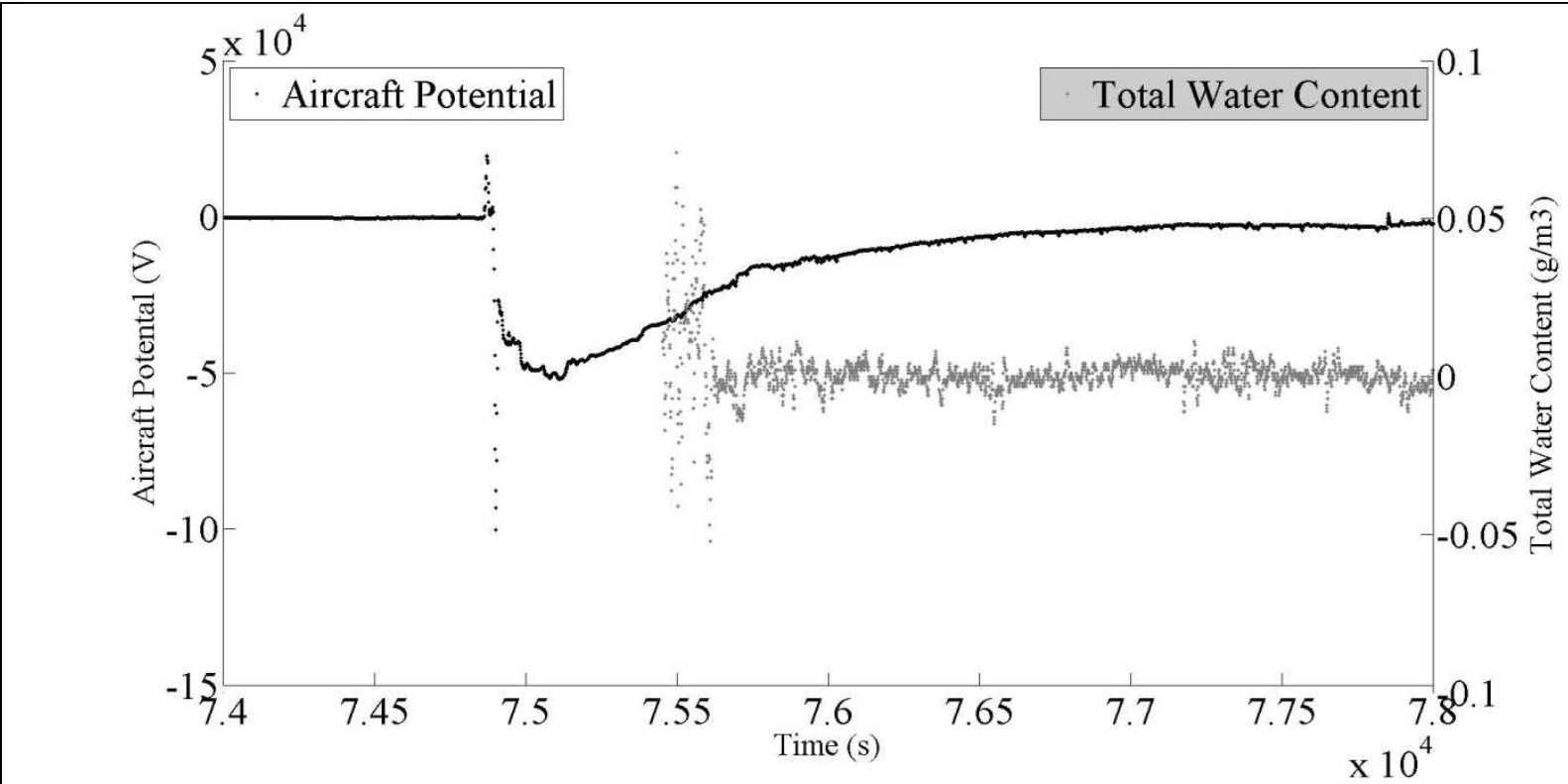

6a - Flight 19 of the Darwin-2014 campaign.

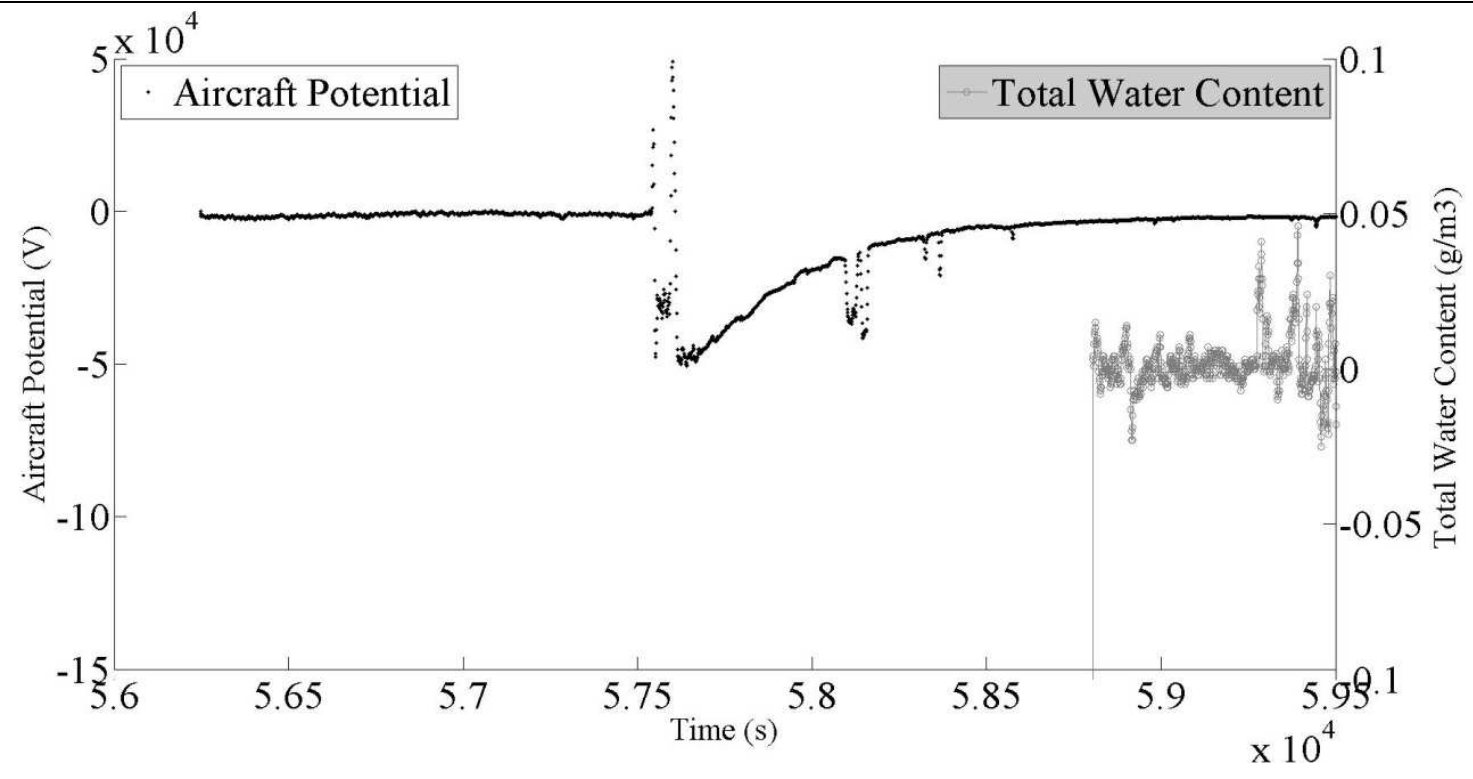

$6 b$ - Flight 15 of the Cayenne-2015 campaign.

Figure 6 : Time histories of aircraft potential (V) (black line) and TWC $\left(\mathrm{gm}^{-3}\right.$ ) from the IKP2 probe (grey line), for flight 19 of Darwin-2014 (6a - top panel) and flight 15 of Cayenne-2015 (6b - bottom panel). Time is in seconds from UTC midnight.

4.2 Comparison between the electrostatic field on the aircraft and the Total Water Content.

The previous section has highlighted the general agreement between the time variations of the local electrostatic field on the aircraft recorded by the field mill at the rear fuselage on the Falcon 20 aircraft and the TWC measured with the IKP2 probe, while flying in glaciated clouds at -37 and $-47^{\circ} \mathrm{C}$. When the IKP2 probe detects the presence of ice particles, a correlated response is observed on each field mill. Based on this observation, the local electrostatic field measured by the field mill at the rear fuselage location has been plotted as a function of the TWC estimated by the IKP2 probe in figures 6 

2015 all data).

441

442

443

444

445

446

447

448

449

450

451

HAIC-HIWC flight campaign clouds were highly dominated by ice crystals (section 1), with only occasional short mixed-phase cloud with low LWC. The electrostatic field recording from the rear fuselage field mill for flight 19 of the Darwin-2014 campaign (measurements at two flight levels of $37^{\circ} \mathrm{C}$ and $-47^{\circ} \mathrm{C}$ ) and flight 15 of the Cayenne-2015 campaign (measurements at four flight levels of approximately $-35,-22,-12$, and $-10^{\circ} \mathrm{C}$ ) have been plotted on figure 7. For Darwin-2014 flight 19, there were no mixed-phase or liquid regions identified. For Cayenne-2015 flight 15, there were a total of 71 seconds in four brief mixed-phase cloud periods, with maximum period-average cloud liquid water content of about $0.1 \mathrm{~g} . \mathrm{m}^{-3}$. The response of the field mills appears to be almost exclusively associated to ice clouds. For each case, linear regressions of the form $\mathrm{E}_{\mathrm{i}}=$ coefficient $\times T W C$ have been fit to the data, and are represented as grey lines on the plots. The characteristics of each flight and the regression statistics are summarized in table 6.

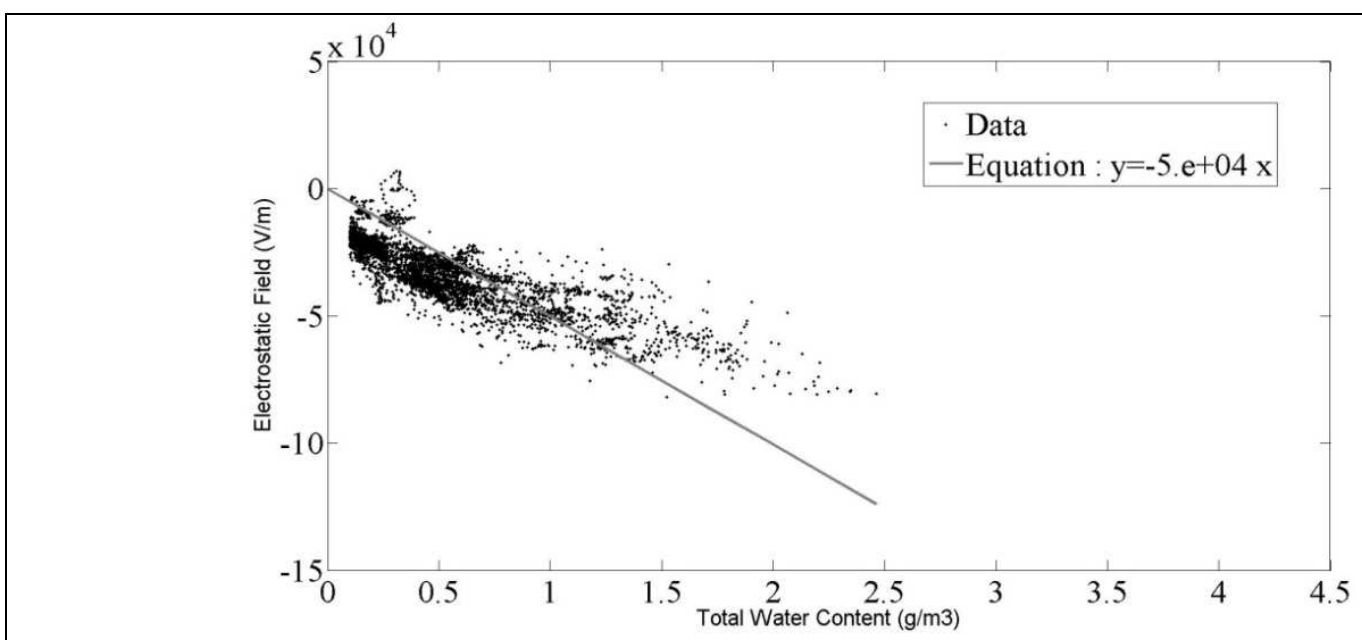

7a: Flight 19 of the Darwin-2014 campaign.

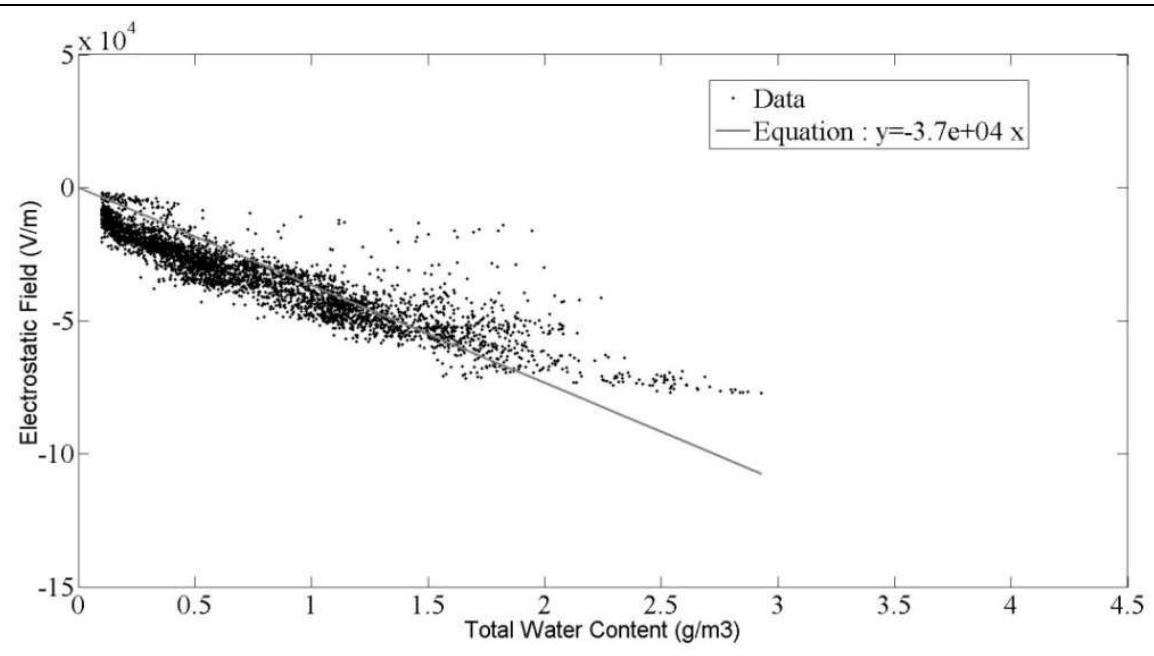

7b: Flight 15 of the Cayenne-2015 campaign. 


\begin{tabular}{|c|c|c|}
\hline Information & FS140019 & FS150015 \\
\hline Date & $02 / 09 / 2014$ & $05 / 16 / 2015$ \\
\hline Take-off/ landing (UTC) & $20: 48$ / 00:14 & $16: 01 / 18: 33$ \\
\hline \multirow{3}{*}{ Flight altitude (km) } & Two flight levels. & Around four flight levels. \\
\hline & & \\
\hline & $11 \mathrm{~km}$ and $12.3 \mathrm{~km}$ & $11 \mathrm{~km} ; 9 \mathrm{~km} ; 7.5 \mathrm{~km} ; 7 \mathrm{~km}$ \\
\hline Temperature $\left({ }^{\circ} \mathrm{C}\right)$ & $-20,-30$ & $-35,-20,-10$ \\
\hline True airspeed $\left(\mathrm{ms}^{-1}\right)$ & 185 & $160-180$ \\
\hline TWC maximum $\left(\mathrm{gm}^{-3}\right)$ & 3.0 & 3.5 \\
\hline $\begin{array}{l}\text { Regression gain coefficient } \\
\qquad(\mathrm{V} / \mathrm{m}) /\left(\mathrm{gm}^{-3}\right)\end{array}$ & -50000 & -37000 \\
\hline $\begin{array}{c}\text { Regression Correlation } \\
\text { coefficient }\end{array}$ & 0.83 & 0.91 \\
\hline $\begin{array}{l}\text { Number of points for the } \\
\text { regression }\end{array}$ & 4224 & 4053 \\
\hline
\end{tabular}

fuselage field mill in function of the TWC (on x-axis - Unit: $g . \mathrm{m}^{-3}$ - black dots). The linear best fit through the origin is shown as the grey line in both plots.

Table 6 : Features of flight FS140019 (Darwin-2014) and flight FS150015 (Cayenne-2015). 


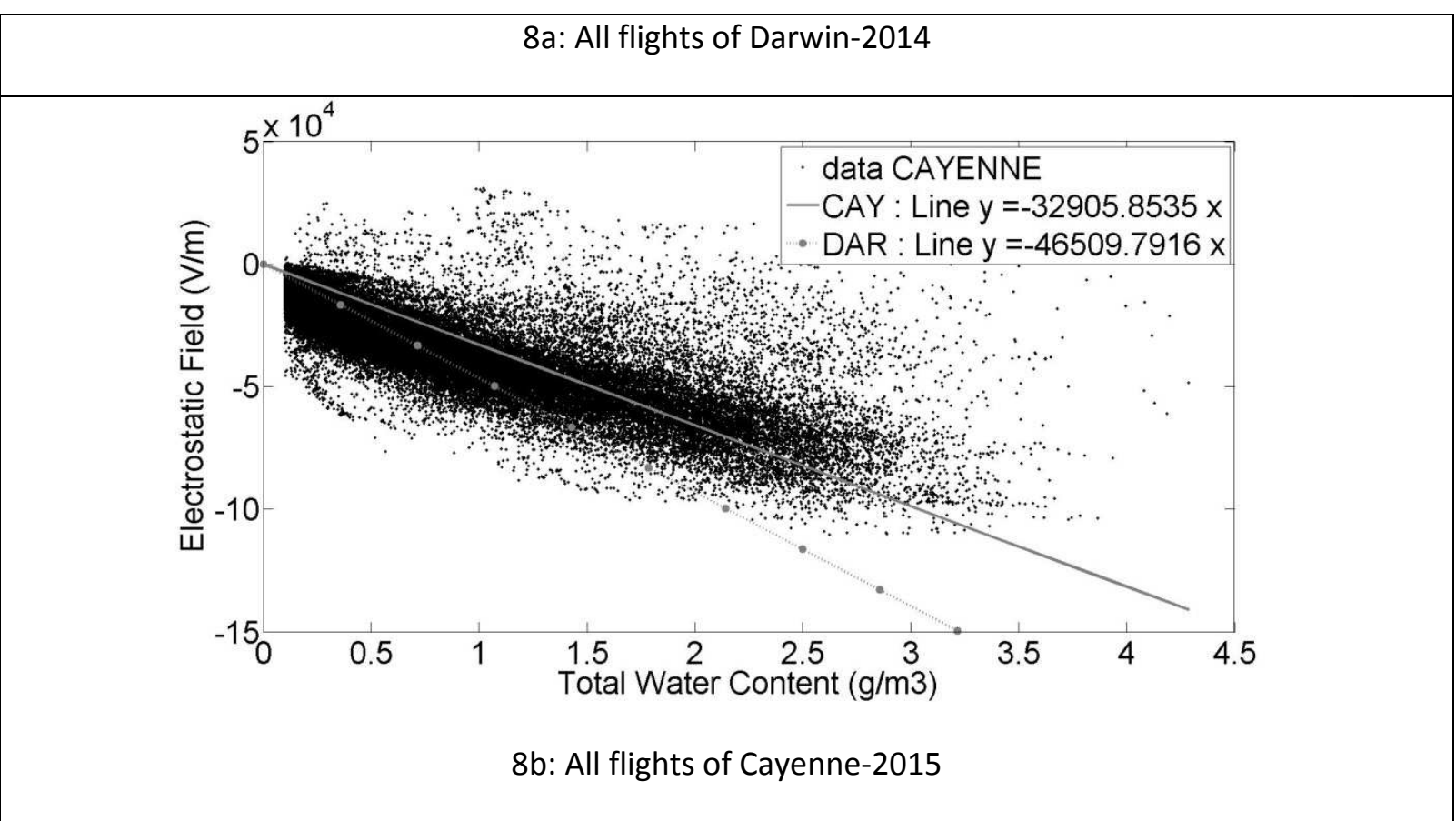

Figure 8 : Same as figure 6 for all flights of Darwin-2014 (8a - top panel) and Cayenne-2015 (8b - bottom panel). The linear best fit through the origin is shown as the grey line in both plots.

In order to estimate the dispersion of these results, separate fits have been derived for each individual flight. A mean value and a standard deviation based on the results for each flight, has been calculated and compared to the gain found with all campaign flights. For the Darwin-2014 campaign, the mean of the individual gain coefficients is 50000 , which is similar to the overall gain of 47000 $(\mathrm{V} / \mathrm{m}) /\left(\mathrm{gm}^{-3}\right)$. Similar results were found for the Cayenne-2015 campaign. For both campaigns, the standard deviation is small. The Darwin-2014 and Cayenne-2015 correlation coefficients for all flights are also include in table 7 , both being about 0.8 , and confirming a good correlation between the electric field and TWC. Within each campaign, the relationship between the electric field and the TWC seems reasonably reproducible. However, there is clearly a stronger electric field response to clouds in Darwin-2014 than in Cayenne-2015, an observation that will be discussed further below. The Cayenne gain coefficient is approximately 32\% lower than that for Darwin. Furthermore, for a given TWC, there is a fairly large scatter in the possible electrostatic field values. This is at least partially due the expected scatter in the IKP2 due to the assumption of ice saturation BWV, and also due to the very large differences in the sample volumes of the two parameters.

Table 7 : Statistics on electrostatic field versus TWC for both campaigns.

Darwin-2014

Cayenne-2015

Number of flights used

(noted $\mathrm{Nb}$ )

Mean of individual gain

coefficients ( $\mathrm{Nb}$ flights)

$(\mathrm{V} / \mathrm{m}) /\left(\mathrm{g} \cdot \mathrm{m}^{-3}\right)$ 


\begin{tabular}{|c|c|c|}
\hline Number of point in the statistics & 70000 & 80000 \\
\hline $\begin{array}{l}\text { Gain coefficient estimated using } \\
\text { all data from Nb flights } \\
\qquad(\mathrm{V} / \mathrm{m}) /\left(\mathrm{g} \cdot \mathrm{m}^{-3}\right)\end{array}$ & -47000 & -33000 \\
\hline $\begin{array}{l}\text { Correlation coefficient on the } \\
\qquad \mathrm{Nb} \text { flights }\end{array}$ & 0.86 & 0.83 \\
\hline Conclusion & $E_{S A} \sim-47000 \times T W C$ & $\mathrm{E}_{\mathrm{SA}} \sim-34000 \times \mathrm{TWC}$ \\
\hline TWC maximum $\left(\mathrm{g} \cdot \mathrm{m}^{-3}\right)$ & 3.57 & 4.29 \\
\hline TWC mean (g.m ${ }^{-3}$ ) & 0.74 & 0.74 \\
\hline Standard deviation $\left(\mathrm{g} \cdot \mathrm{m}^{-3}\right)$ & 0.6 & 0.7 \\
\hline
\end{tabular}

479

480

481

482

483

484

485

486

487

488

489

490

491

492

493

4.3 Comparison between the aircraft potential and the Total Water Content.

The magnitude and variation of the electrostatic field on the aircraft skin depends on the atmospheric electrostatic field around the aircraft and the net electric charge of the aircraft. This latter depends on the balance current on the aircraft fuselage and is tied to the particle concentration. Indeed, charge will mainly accumulate on the aircraft by the triboelectric effect and by the engine exhaust. This accumulation will induce an increase of the aircraft potential. It is assumed here that the aircraft potential variation comes mainly from the triboelectric effect and the corona effect. As in section $4 a$, statistics have been calculated following the same principle, but this time for the module of the aircraft potential versus TWC. Figure 9 contains results from all flights of Darwin-2014 (9a) and Cayenne-2015 (9b). The grey line on the figures represents the linear regression fit for each dataset. The gain coefficient is $520000 \mathrm{~V} /\left(\mathrm{gm}^{-3}\right)$ for Darwin-2014 and 190000 $\mathrm{V} /\left(\mathrm{gm}^{-3}\right)$ for Cayenne-2015. The mean and standard deviation of the TWCs obtained from the flights of each campaign are similar. The correlation coefficients for all flights, by campaign, are 0.8 for Darwin-14 and 0.7 for Cayenne-2015. 


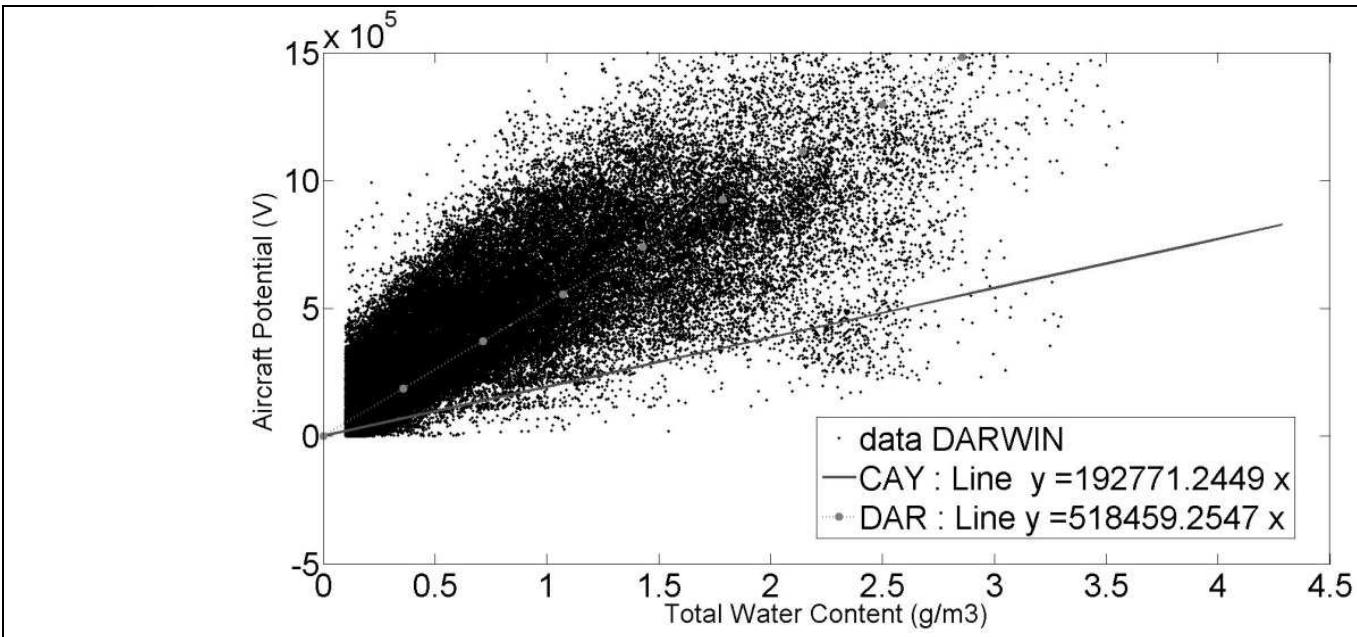

9a: Darwin-2014

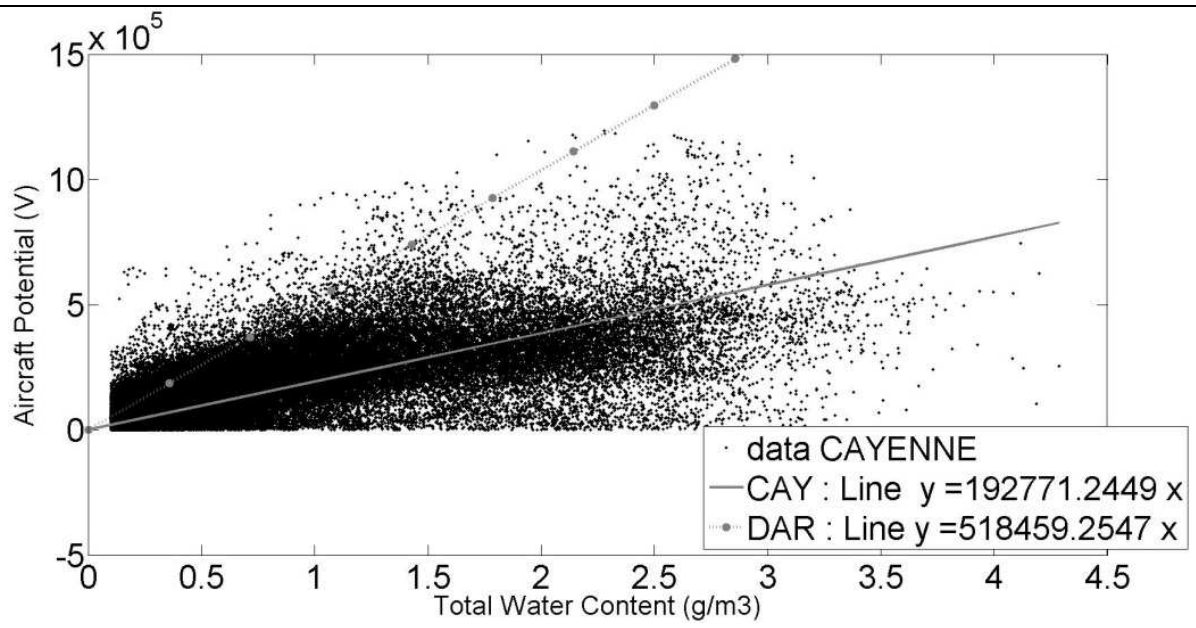

9b: Cayenne-2015

Figure 9 : Module of the aircraft potential versus TWC, for Darwin-2014 (9a-top panel), and Cayenne-2015 (9b-bottom panel). Data are from all flight described in table 7. The linear best fit through the origin is shown as the grey line in both plots

Finally, if we merge the information from all flights of both campaigns (Darwin-2014 and Cayenne2015), an overall gain coefficient and correlation coefficient is found between the aircraft potential and the TWC. Based on this result, we can establish the following general relationship:

$$
V_{a}=g * T W C
$$

where $V_{a}$ is the aircraft potential, TWC is the total water content and $g$ is the regression gain parameter. As in the previous section for electrostatic field, there is a fairly large scatter in expected aircraft potential for a given TWC.

The quantiles ( $15 \%, 50 \%$ and $85 \%$ ) of aircraft potential for each $0.2 \mathrm{~g} \cdot \mathrm{m}^{-3}$ TWC interval have been calculated to complete the results shown on figures 9. Results are plotted in figure 10 for both campaigns (Darwin-2014 in black lines and Cayenne-2015 in grey lines). This plot highlights the differences between the two campaigns and quantifies the variability of results within a campaign. 
For each campaign, for a fixed aircraft potential, the range of observed TWC values is very large. For example, for Darwin-2014, the $15-85 \%$ quantile TWCs for a $500 \mathrm{kV}$ are 0.5 to $1.5 \mathrm{~g} . \mathrm{m}^{-3}$. For Cayenne2015 , this $500 \mathrm{kV}$ is reached $15 \%$ of time only for TWCs greater than about $2.25 \mathrm{~g} . \mathrm{m}^{-3}$.

The wide range of IWC values for a given aircraft potential, within a campaign, could in part be explained by scatter in the IKP2 measurements and sample volume differences. However, this cannot explain the overall scale differences of the aircraft potential response to TWC observed between the two campaigns.

At $1.5 \mathrm{~g} . \mathrm{m}^{-3}$, the $15-85 \%$ quantile aircraft potential is $100-500 \mathrm{kV}$ for Cayenne-2015 versus $500-1000$

In spite of the fact that a similar distribution of TWC values was observed in both campaigns, only a small percentage of aircraft potential values greater than $500 \mathrm{kV}$, was found in Cayenne-2015, where such values were common in the Darwin-2014 data.

The form of equation (4) implies that outside cloud, in fair weather conditions, the aircraft potential should be zero. In real flight condition, others effects than those inducing by particles collisions must be taken into account. Indeed, the corona effect or the engine exhaust (as illustrated before with figures 6) would be considered. Concerning the Falcon 20 aircraft potential due to engine charging, Figure 6 shows that this charging effect occurred from take-off to about $11 \mathrm{~km}$ altitude; the maximum effect is observed around $4 \mathrm{~km}$ altitude $(\mathrm{Va} \sim-50 \mathrm{kV})$; then, as the aircraft altitude increases, the potential magnitude decreases and reaches a value as low as $2 \mathrm{kV}$, closed to the AMPERA network threshold. When the aircraft is flying inside iced clouds, its potential reaches hundreds of $\mathrm{kV}$, a magnitude much larger than the network threshold.

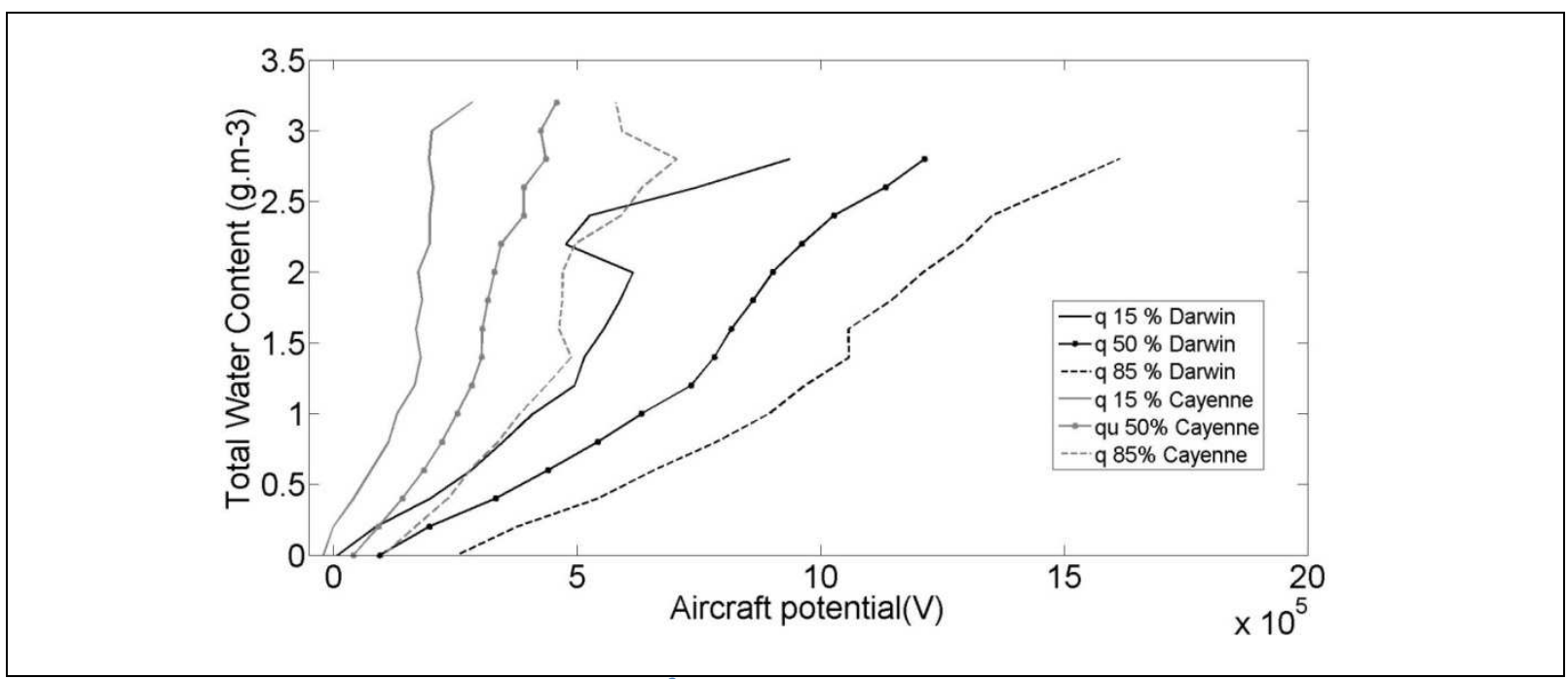

Figure 10 : Quantiles of aircraft potential in $0.2 \mathrm{gm}^{-3}$ TWC intervals (Darwin-2014 black, Cayenne-2015 grey). The quantile $15 \%$ is in solid line; the quantile $50 \%$ is in solid line with circle and the quantile $85 \%$ is in dashed line. Aircraft potential on x-axis (Unit : V). Total Water content on y-axis. (Unit : g. $\mathrm{m}^{-3}$ ).

Figure 10 underscores the limitation of our methodology in estimating TWC. Despite these limitations, the collective data from all flights of both campaigns has consistently established a relationship between the aircraft potential and the IWC for every flight. In its current state of development, the methodology gives a realistic estimation of TWC. 


\section{Discussion}

5.1 Relationship between the total water content and the aircraft potential.

The starting point in understanding equation 4 and in defining parameters related to the gain parameter $\mathrm{g}$, lies in the electrical charging and discharging processes of the aircraft during flight. A cloud is composed of multiple hydrometeors. During the HAIC-HIWC campaign, the aircraft flew through convective cloud dominated by ice particles that impacted the fuselage of the aircraft. These impacts led to electrical charge exchanges between the aircraft fuselage and the particles by the triboelectric effect. It produced a charging process equivalent to a charge current (the charge current is noted Ic). This charging phenomenon is a known process, observed by Nanevicz and Tanner (1961, 1974), Boulay and Laroche (1982), and Laroche (1985). From 1940 to 1980, the phenomenon was noted as a source of radio-electric disturbance for navigational systems (Stimmel, 1946). The mitigation of this phenomenon consists of installing passive potential dischargers for corona discharge, which act to decrease the aircraft potential. Many measurement campaigns have been conducted worldwide to study electrical parameters during aircraft flight. These campaigns have revealed that the charge (Q) transferred by impact of a hydrometeor on the aircraft fuselage was on the average 10 to 20pC (Tanner, 1961; Naneviecz, 1974; Illingworth, 1986). The amount of the charge deposited on the aircraft varied considerably from cloud to cloud and even from particle to particle in the same cloud (Tanner, 1961). The amount appeared to be a function of the aircraft speed (Illingsworth, 1986; Tanner, 1961), the shape and the size of the particles and environmental parameters such as the temperature (Saunders, 2004).

The intensity of the charging current $\left(\mathrm{I}_{\mathrm{c}}\right)$ is proportional to the product of the average particle charge transferred at each collision and the number of particles striking the aircraft per unit of time. This second parameter is proportional to the particle concentration $(N)$ in cloud, the aircraft speed $\left(V_{p}\right)$ and the effective impact surface of impingement $\left(S_{\text {eff }}\right.$ Tanner, 1961). The charging current increases the net electrical charge of the aircraft and the aircraft potential (Illingsworth, 1986; Larigaldie, 1980; Boulay, 1982). The expression for the charging current is given by:

$$
I_{c}=\mathrm{V}_{\mathrm{p}} * \mathrm{~S}_{\mathrm{eff}} * \mathrm{Q} * \mathrm{~N}
$$

The increase of the aircraft potential is limited by the ignition of electrical corona discharges from the sharpest points of the aircraft. A corona discharge initiates when the electrical field on the aircraft skin reaches the air breakdown field (Boulay, 1982). The discharge current $\left(I_{d}\right)$ associated with the corona depends on the aircraft potential $\left(\mathrm{V}_{\mathrm{a}}\right)$, the air density and the aircraft geometry. Using a first order approximation, the corona current can be represented by equation (5) below, with $\mathrm{k}$ being a scale coefficient. As mentioned in Boulay (1982), the temperature, pressure and the aircraft geometry play important roles on the manifestation of the discharged current, and more precisely in the $\mathrm{k}$ coefficient.

$$
I_{d}=k * V_{a}
$$

In Boulay and Laroche (1982), a Gloster Meteor aircraft (with a cross-section of $8.32 \mathrm{~m}^{2}$ ) was instrumented with field mills sensors, triboelectric current measurement on instrumented dielectric panel. The aircraft was flown in various atmospheric conditions. As part of their results, they measured the discharge current as a function of the aircraft potential. Based on these results, the $k$ 
coefficient for an aircraft of this size and a potential of approximately $100 \mathrm{kV}$, flying at $200 \mathrm{~m} \cdot \mathrm{s}^{-1}$, was estimated at $400 \mu \mathrm{A} . \mathrm{kV}^{-1}$.

The variation of the aircraft potential $V_{a}$ is given by the following relationship:

$$
V_{a}(t)=\frac{1}{C_{a}} \int_{0}^{t}\left(I_{c}-I_{d}\left(V_{a}, \ldots\right)\right) d u
$$

The relationship between charging and discharging current is obtained by taking the time derivative of equation (7),

$$
I_{c}=I_{d}+C_{a} \frac{d V_{a}}{d t}
$$

Calculation of the displacement current $\left(C_{a} \frac{d V_{a}}{d t}\right)$ shows that this parameter remains small compared to the charging and discharging current. If the charge equilibrium is reached quickly relative to the time variation of the measurement, a steady state can be assumed leading to:

$$
I_{c}=I_{d}\left(k V_{a}, \ldots\right)
$$

Based on the assumption of the electrostatic equilibrium (equation 9) and using approximations detailed previously for the charging current (equation5) and the discharging current (equation 6), the aircraft potential can be linked to the particle concentration $\mathrm{N}$ by the following formula:

$$
N=\frac{\left(k * V_{a}\right)}{V_{p}(z) \times Q(\text { Dm, class of hydrometeor }) \times S_{\text {eff }}(D m, S a)}
$$

where $V_{p}$ is the aircraft velocity (typically a function of altitude during flight); $Q$, the charge transferred by collision (a function of the median diameter, $\mathrm{Dm}$, and class of hydrometeors); $\mathrm{S}_{\mathrm{eff}}$, the effective impingement surface (dependent on the impingement coefficient, the size of particles and the aircraft cross-sectional area); $k$, the correlation scale parameter; $C_{a}$, the aircraft capacitance and $V_{a}$, the aircraft potential. The implicit assumption associated with equation (9) is that the charging conditions are representative of the average conditions existing on all the aircraft surfaces.

TWC can be estimated from the particle concentration, $N$ (detailed in equation 10), taking into account the particle size distribution. In the section 4 , it was contended that aircraft potential and TWC were related through a linear coefficient g (equation 4). Based on equation 10, the parameters determining $g$ can be defined. The coefficient $g$ depends mainly on the particle charge transferred at each collision, the effective impingement surface, the aircraft velocity, the aircraft electrical capacitance, and the particle diameter $\left(D_{m}\right)$. A more detailed relationship between the TWC and the aircraft potential can be formulated as follows:

$$
V_{a}=g\left(N, Q, S_{e f f}, V_{p}, C_{a}, D_{m}, \frac{1}{k}\right) \times T W C\left(D_{m}, N\right)
$$

5.2 Discussion of the difference of correlation gain coefficient found between the two campaigns.

In section 4, the aircraft potential, inferred from the electric field measurements recorded by the field mills was compared to the independently measured TWC. Linear fits between these parameters highlighted a strong positive correlation, with dependent factors that are described in equation (11). 

campaigns, investigations have been conducted in order to try to explain the difference in terms of gain coefficient discussed in section 4 .

614

615

616

617

618

619

620

621

622

623

624

625

626

627

628

629

630

631

632

633

634

635

636

637

638

639

640

641

642

643

644

645

646

647

648

649

650

651

During the Darwin-2014 and Cayenne-2015 campaigns, the same Falcon-20 aircraft with the same probe configuration was used. Consequently, of those parameters listed in equation (11), the effective impingement surface $\left(S_{\text {eff }}\right)$, the aircraft speed $\left(V_{p}\right)$ and the aircraft capacitance $\left(C_{a}\right)$ are the same for both measurements campaigns. The aircraft true airspeed was about $190 \mathrm{~m} . \mathrm{s}^{-1}$ during each flight of the Darwin and Cayenne campaigns. The aircraft capacitance deduced from the Poisson calculations for the Falcon-20 mesh, was around 500 pF.

The effective intercepting area of the aircraft, i.e. the cross-sectional area of the aircraft weighted by the impingement coefficient, is typically $60 \%$ of the aircraft projected frontal area (Tanner, 1961). For the Falcon 20 aircraft, the cross-sectional area is $12.3 \mathrm{~m}^{2}$. The impingement coefficient depends on the size of particles and a capture coefficient. This coefficient reflects that the larger particles (larger than $50 \mu \mathrm{m}$ ) have more chance to impact the fuselage because of their ballistic trajectory. In contrast, smaller particles tend to be diverted away by the airflow streamlines (Tanner, 1961). Experimental investigations have been performed on the impingement efficiencies, taking into account cloud parameters such as the LWC, the size of particles, aerodynamic characteristics such as the airfoil shape and the angle of attack (Papadakis, 2000). Examples of the magnitudes of impingement efficiencies and the link to particle size have been given in Papadakis (2000), who found impingement efficiencies of $0.4,0.6$ and 0.7 for particles with $11.5 \mu \mathrm{m}, 21$ and $92 \mu \mathrm{m}$ median volumetric diameters respectively.

As mentioned before, the impingement coefficient but also the charges of the particles depend on the particles spectra dimension. Equation (11), deduced from equation (4), formulates a linear relationship between $\mathrm{Va}$ and TWC but does not demonstrate it: if $\mathrm{N}$, the concentration of cloud particles can be considered as producing a mean elementary charge $Q$, with a mean effective impact area Seff, then the charging current Ic can be described by equation (5). It is important to take into account the whole spectra of particles. The relationship put in advance in this article comes from the best fit between the two set of data. We do not propose a rational to predict a simple linear relationship between potential and TWC.

Other parameters such as the aircraft accelerations, wind direction, wind speed and internal parameters of the field mill (temperature, motor current) have been compared. These parameters were similar during both campaigns.

The difference in the magnitude of the regression gain coefficient, g, could possibly be explained by differing meteorological conditions. During both campaigns, similar MCSs were sampled at a variety of altitudes. Consequently, it is contended here that gain coefficient differences between the two campaigns might be explained by differences in the particle size distribution and/or the atmospheric conditions (temperature and pressure), which play a role in the charging of the aircraft through the tribo-electric effect and the discharging through the k coefficient.

The aircraft configuration and maintenance have also been checked in order to understand the gain differences between Darwin-2014 and Cayenne-2015 campaigns. Between both campaigns, the aircraft and probes configuration on the Falcon 20 aircraft have been the same. Nevertheless, 
changes on aircraft maintenance occurred before the beginning of the Cayenne-2015 campaign. Among them, the painting and the static wings on the nose of the plane have changed. These changes may have an impact on the charging (for the painting) or the discharging (for the static wings) of the aircraft.

\section{The Influence of temperature}

There were some differences in the flight environments between Darwin-2014 and the Cayenne2015 campaigns. The former campaign collected data primarily in the -30 and $-40^{\circ} \mathrm{C}$ temperature intervals, while the latter additionally focused on the -10 and -50 temperature intervals in order to achieve the desired HAIC-HIWC data collection at all 4 temperature intervals. The higher occurrence of mixed-phase clouds in Cayenne (section 1), although still rare, may have contributed somewhat to differences in the particle microphysical characteristics, for example for dense particles due to riming. Furthermore, the differences in the temperature levels flown in the two campaigns may have contributed to net differences in the atmospheric pressure and true airspeed that could affect equation (11), although the campaign differences were not abundantly different. Perhaps the most notable difference in Cayenne-2015 was the large fraction of data from the $-10^{\circ} \mathrm{C}$ level. Leroy et al. (2017) have shown that the median mass diameter (MMD) of particles increased significantly with temperature, implying that the Cayenne-2015 dataset could be composed of particle collectively larger than Darwin-2014.

The impact of the air temperature and consequently the pressure and altitude are exemplified through the study of Cayenne-2015 flight 13 (FS150013) and based on statistics from all flights. Time history measurements of flight $13(05 / 18 / 2015)$ are shown in the four panels of figure 11 , including aircraft potential (top left), TWC (top right), altitude (bottom left), and static air temperature (bottom right). During this flight, the aircraft flew at three different level (approximately $7 \mathrm{~km}, 10 \mathrm{~km}$ and 12 $\mathrm{km}$ ), corresponding to approximately $-10^{\circ} \mathrm{C},-30^{\circ} \mathrm{C}$ and $-45^{\circ} \mathrm{C}$ in air temperature. The magnitude and the fluctuations of the retrieved aircraft potential do not seem to be linked to the changes of air temperature. This point is further supported by the following analysis. TWC and aircraft potential measurements have been sorted into three $10^{\circ} \mathrm{C}$ intervals, centered on $-20^{\circ} \mathrm{C},-30^{\circ} \mathrm{C}$, and $-40^{\circ} \mathrm{C}$. Then quantiles ( $15 \%, 50 \%$ and $85 \%$ ) of aircraft potential have been calculated for each 0.2 g.m $\mathrm{m}^{-3} \mathrm{TWC}$ interval. Results are presented for $-20,-30$, and $-40^{\circ} \mathrm{C}$ in figures $11 \mathrm{~b}-11 \mathrm{~d}$ respectively. On each figure, Darwin-2014 and Cayenne-2015 results are shown as black and grey curves. The numbers of points used for the statistics for each campaign are contained in figures 11e and 11f. Note that the Darwin2014 aircraft potential results are consistently higher than Cayenne-2015 for all temperature intervals. Furthermore, there is no obvious change in the magnitude of the aircraft potential for the same TWC with changes in temperature for either campaign. These results suggest that the pressure level, and consequently the temperature and altitude have no obvious impact on the linear regression gain coefficient between the aircraft potential and the TWC, obtained for both campaigns. Variations of temperature and pressure cannot alone explain the gain difference in aircraft potential versus TWC observed between the two campaigns. 


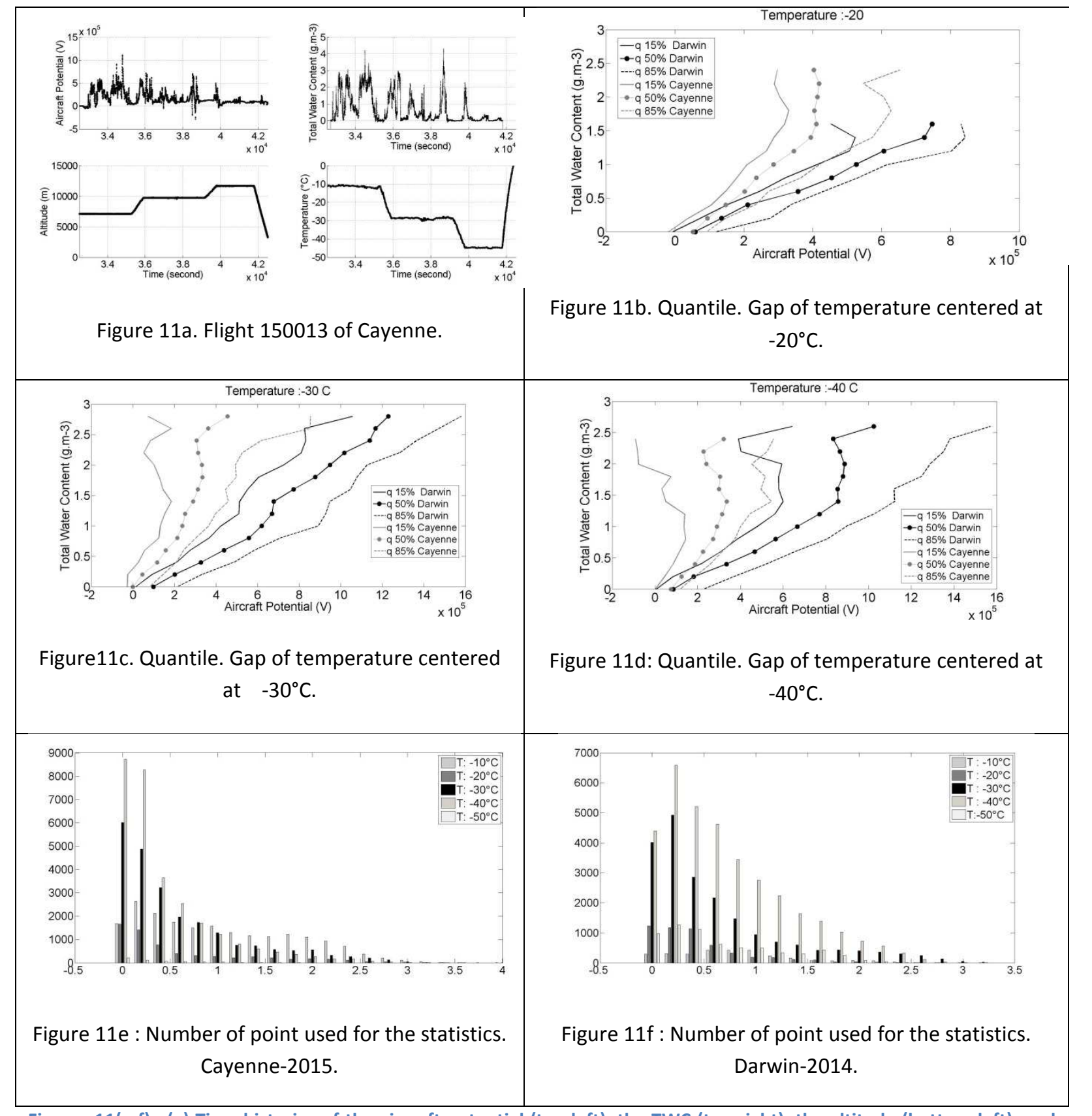

Figures 11(a-f) : (a) Time histories of the aircraft potential (top left), the TWC (top right), the altitude (bottom left), and the temperature (bottom right), for flight FS150013 of the Cayenne-2015 campaign; (b)quantiles of aircraft potential in $0.2 \mathrm{gm}^{-3}$ TWC intervals (Darwin-2014 black, Cayenne-2015 grey), for the -20 C temperature interval; (c) as in (b) but for the $-30 \mathrm{C}$ temperature intervals; (d) as in (b) for the $-40 \mathrm{C}$ temperature interval; (e) number of points used in the Cayenne-2015 statistics, and (f) number of points used in the Darwin-2014 statistics. Times in (a) are seconds after UTC midnight. Quantiles for (b), (c), and (d) as follows: (15\% in solid line, $50 \%$ in solid line with circle, $85 \%$ in dashed line).

The reason for the gain differences between the electric field measurements versus TWC during Darwin-2014 and Cayenne-2015 remain an unresolved question. There is nothing in the IKP2 TWC measurements to suggest an overall TWC scale factor difference between the two campaigns. The statistics of the IKP2 TWC measurements in Cayenne-2015 were similar to those of Darwin-2014, with Cayenne-2015 TWCs in fact being a little higher than those of Darwin-2014, in the opposite direction as that required to explain the higher aircraft potential readings in Darwin-2014. An overall 30 \% TWC measurement error between Darwin and Cayenne is not considered possible. Further work is required to investigate other possible influences. Ice particle properties such as morphology, 
and PSD bulk properties such as median and other percentile mass diameters may have an effect on the charge transfer on impact with the fuselage.

\section{Conclusions}

During the HAIC-HIWC campaign, airborne instrumentation including microphysical probes and electric field probes have been used to sample mostly glaciated high TWC convective cloud with only rare occurrences of mixed-phase. The data were collected during the Darwin-2014 and the Cayenne2015 flight campaigns. The comparison of data recorded by a network of field mills installed flush on the aircraft fuselage (the AMPERA system) and on PMS canisters under the aircraft wings, and the TWC estimated by the IKP2 probe revealed a good agreement in terms of temporal variation. Statistical analysis confirmed the good correlation between the aircraft potential and the TWC. The linear regression gain and correlation coefficients for a fit through the origin have been calculated for each flight of each measurement campaign Gain coefficients $\left(\mathrm{V}\right.$ per $\left.\mathrm{gm}^{-3}\right)$ were similar from one flight to another within the same measurement campaign, but were about $63 \%$ lower for Cayenne relative to Darwin. It was speculated that the main impact affecting the gain difference could come from the particle size distribution (morphology, median mass diameter etc.) and possibly the temperature.

Based on these results, a new approach for estimating TWC is proposed based on the data delivered by the AMPERA system, and using the empirical gain coefficients derived from the HAIC-HIWC dataset. Through this new approach, the whole aircraft acts as the sensor. Thus, for flights with the same type of aircraft and the same AMPERA configuration, the coefficients reported here could be applied as a first-order approximation for estimating TWC from the aircraft potential. Nevertheless, the methodology does not allow obtaining an IWC value at a high degree of accuracy. This method would be useful for real-time detection on commercial aircraft as a first guess for TWC. This new concept could deliver a first order of IWC conditions and provide a warning to pilots of commercial aircraft.

This study has brought evidence of the relationship between the electrical potential and the total water content. Future studies have to be performed in order to analyse the correlation between the aircraft electrical charging and microphysical parameters as the size spectrum of the impacting cloud particles or the properties of ice crystals and the aerosol types.

\section{Acknowledgements}

Major European HAIC-HIWC campaign and HAIC research funding was provided from (i) the European Commission Seventh Framework Program in research, technological development and demonstration under grant agreement $n^{\circ} A C P 2-G A-2012-314314$, (ii) the European Aviation Safety Agency (EASA) Research Program under service contract $n^{\circ}$ EASA.2013.FC27. Major North American funding for flight campaigns and associated research was provided by the FAA William Hughes Technical Center and Aviation Weather Research Program, the NASA Aeronautics Research Mission Directorate Aviation Safety Program, the Boeing Co., Environment Canada, the National Research Council of Canada, and Transport Canada. Further funding was provided by the Ice Crystal Consortium.

For the Falcon-20, primary support was provided by the SAFIRE facility for the scientific airborne operations. SAFIRE (http://www.safire.fr) is a joint facility of CNRS, Météo-France and CNES. 
NCAR/EOL provided access to some of the datasets used in this article under the sponsorship of the National Science Foundation https://data.eol.ucar.edu/.

\section{References}

Abel S. J., Cotton R. J., Barret P.A., Vance A. K., 2014: A comparison of ice water content measurement techniques on the FAMM Bae-146 aircraft, Atmos. Meas. Tech, 7, 3007-3022.

Boulay J. L., Laroche P., 1982: Aircraft Potential Variations In flight, Int. Aerospace Conference on Lightning and Static Electricity, 19.

Bourdeau C., Chauzy S., 1989: Maximum electric charge of a hydrometeor in the electric field of a thundercloud. J. Geoph. Res., 94, 13121 - 13126.

Bateman M. G., Stewart M. F., Blakeslee R. J., Podgorny S. J., Christian H. J., Mach D. M., Bailey J. C., Daskar D., 2007: A low noise, Microprocessor-Controlled, Internally Digitizing Roating-Vane Electric Field Mill for Airborne Platforms. J. Atmos. and Ocea. Tech., 24, 1245-1255.

Baumgardner, D., and A. Rodi, 1989: Laboratory and wind tunnel evaluations of the Rosemount icing detector. J. Atmos. Oceanic Technol., 6, 971-979.

Baumgardner D., Brenguier J.L., bucholtez A., Coe H., DeMot P., Garrett T.J., Gayet J.F., Herman M., Heymsfield A., Korolev A., Krämer M., Petzold A/, Strapp W., Pilewskie P., Taylor J., Twohy C., Wendish M., Bachalo W., Chuang P., 2011: Airborne instruments to measure atmospheric aerosol particles, clouds and radiation: A cook's tour of mature and emerging technology. Atmos. Research, 102, 10-29.

Brenguier J.-L., W. D. Bachalo, P. Y. Chuang, B. M. Esposito, J. Fugal, T. Garrett, J.-F. Gayet, H. Gerber, A. Heymsfield, A. Kokhanovsky, A. Korolev, R. P. Lawson, D. R. Rogers, R. A. Shaw, W. Strapp and M. Wendish, 2013: In Situ Measurements of Cloud and Precipitation Particles. In Airborne Measurements for Environmental Research: Methods and Instruments, first edition by $\mathrm{M}$. Wendish and J.-L. Brenguier. 2013. Wiley-VCH Verlag GmbH \& Co. KGaA.

Chauzy S., Médale J.-C., Prieur S., Soula S., 1991: Multilevel measurement of the electric field underneath a thundercloud. 1. A new system and the associated data processing. J. G. R., 96, 22319-22326.

Christian Jr. H. J., 1976: Design and evaluation of balloon-borne electric field sensor, Rice University, Thesis, 78p.

Cober, S.G., G.A. Isaac, and A.V. Korolev, 2001: Assessing the Rosemount Icing Detector with In Situ Measurements. J. Atmos. Oceanic Technol., 18, 515-528, doi: 10.1175/15200426(2001)018<0515:ATRIDW>2.0.CO;2.

Davison, C. R., MacLeod, J. D., Strapp, J. W., and Buttsworth, D. R., 2008: Isokinetic Total Water Content Probe in a Naturally Aspirating Configuration: Initial Aerodynamic Design and Testing, 46th AIAA Aerospace Sciences Meeting and Exhibit, Jan. 10, 2008, Reno, Nevada, AIAA-20080435. 
Davison, C.R., MacLeod, J.D., and Strapp, J.W., 2009: Naturally Aspirating Isokinetic Total Water Content Probe: Evaporator Design and Testing, 1st AIAA Atmospheric and Space Environments Conference, 25 June 2009, San Antonio, Texas, AIAA-2009-3861.

Davison, C. R., Landreville, C., and MacLeod, J. D., 2010a : Initial Development and Testing of Isokinetic Probe to Measure Total Water Content During Ground and Airborne Testing, NRC, LTR-GTL-2010-0002, Ottawa, Mar. 2010.

Davison, C.R., MacLeod, J.D., and Ratvasky, T.P., 2010b: Naturally Aspirating Isokinetic Total Water Content Probe: Preliminary Test Results and Design Modifications, 2nd AIAA Atmospheric and Space Environments Conference, 2-5 August 2010, Toronto, Ontario, AIAA-2010-7530.

Davison, C.R., Ratvasky, T.P., and Lilie, L.E., 2011: Naturally Aspirating Isokinetic Total Water Content Probe: Wind Tunnel Test Results and Design Modifications, SAE 2011 International Conference on Aircraft and Engine Icing and Ground Deicing, 13-17 June 2011, Chicago, Illinois, SAE 201138-0036.

Davison C. R., Strapp J. W., Lilie L, Ratvasky T. P., Dumont C., 2016 : Isokinetic TWC Evaporator Probe : Calculations and Systemic Uncertainty Analysis, $8^{\text {th }}$ AIAA Atmospheric and Space Environments Conference, 18p, 2016-4060.

Davison, Craig R., Dan Fuleki, Jennifer L.Y. Chalmers, and Brian Galeate, 2018: NRC Particle Detection Probe: Transition from Test Cell to Flight Operation. Applied Vehicle Technology: AVT-306, December 2018. Athens: NATO: Science and Technology Organization (STO), 2018.

Delanoe J., Protat A., Jourdan O., Pelon J., Papazzoni M., Dupuy R., Gayet J.-F., Jouan C., 2013: Comparison of Airborne In Situ, Airborne Radar-Lidar, and Spaceborne Radar-Lidar Retrievals of Polar Ice Cloud Properties Sampled during the POLARCAT Campaign, J. Atmos. Ocea. Tech, 30, 57-73.

Delannoy A., Gondot P, 2012: Airborne Measurements of the Charge of Precipitating Particles Related to Radar Reflectivity and Temperature within two Different Convective Clouds, Journal of Aerospace Lab, AL05-02.

Dezitter F., Grandin A., Brenguier J. L., Hervy F., Schlager H., Villedieu P., Zalamansky G., 2013, HAIC (High Altitude Ice Crystals). $5^{\text {th }}$ AIAA Atmospheric and Space Environments Conference Aircraft Icing, 15p

Flegel A. B., 2018: Ice Crystal Icing Research at NASA, American Inst. of Aeronautics and Astronautics, $19 p$.

Fontaine E., Schwarzenboeck A. , Delanoe J., Wobrock W., Leroy D, Rupuy R., Gourbeyre C., Protat A., 2014: constraining mass-diameter relations from hydrometeor images and cloud radar reflectivities in tropical continental and oceanic convective anvils. Atmos. Chem. Phys., 14, 11367-11392. 
Grandin, A., Merle, J-M, Weber, M., Strapp, J.W., Protat, A., and King, P, 2014: AIRBUS Flight Tests in High Total Water Content Regions, 6th AIAA Atmospheric and Space Environments Conference, AIAA AVIATION Forum, (AIAA 2014-2753)http://dx.doi.org/10.2514/6.2014-2753.

Gun R. 1948: Electric Field Intensity Inside of Natural Clouds, J. Applied Physics, 19, 481-484.

Jones, J. J., 1990: Electric Charge Acquired by Airplanes Penetrating Thunderstorms, J. of Geo. Res., 95, No, D10, 16589-16600.

Illingsworth A. J. et al., 1986: Static charging of aircraft by collisions with ice crystals, Rev. Phys. App., 21 (12), 803-808.

Kasemir H. W. 1972: The cylindrical field mill, Meteor. Rundshau, 25, 33-38.Korolev A., Strapp J. W., Isaac G.A., 1998a: The Nevzorov Airborne Hot-Wire LWC-TWC Probe: Principle of Operation and Performance Characteristics, J. Atmos. and Oceanic Tech, 15, 1495-1510.

Keith W.D. et al., 1990: Charging of an aircraft - high velocity collisions Journal of Aircraft, 27 (3), 218.

Korolev, A.V., J.W. Strapp, and G.A. Isaac, 1998a: Evaluation of the accuracy of PMS optical array probes. J. Atmos. Oceanic Technol., 15, 708-720.

Korolev, A.V., J.W. Strapp, and G.A. Isaac, 1998b: The nevzorov airborne hot-wire LWC-TWC probe: principle of operation and performance characteristics. J. Atmos. Ocean. Technol., 15, 14951510.

Korolev A., Isaac G., Cober S., Strapp J.W., Hallet J., 2003: Microphysical characterization of mixedphaseclouds, Q. J. R. Meteorol. Soc., 129, 39-65.Korolev A., Strapp J. W., Isaac G. A., Emery E., 2013: Improved Airborne Hot-Wire Measurements of Ice Water Content in Clouds, J. Atmos. Oceanic Tech., 30, 2121-2131

Korolev, A., G. McFarquhar, P.R. Field, C. Franklin, P. Lawson, Z. Wang, E. Williams, S.J. Abel, D. Axisa, S. Borrmann, J. Crosier, J. Fugal, M. Krämer, U. Lohmann, O. Schlenczek, M. Schnaiter, and M. Wendisch, 2017: Mixed-Phase Clouds: Progress and Challenges. Meteorological Monographs, 58, 5.1-5.50,https://doi.org/10.1175/AMSMONOGRAPHS-D-17-0001.1

Koshak W. J., Bailey J., Christian H. J., Mach D. M., 1994: Aircraft electric field measurements: Calibration and ambient field retrieval, J. Geo. Res., 99, D11, $2281-22792$.

Koshak W. J., 2006: Retrieving Storm Electric Fields from Aircraft Field Mill Data. Part I: Theory, L. Atmos. Ocea. Tech, 23, 1289-1302.

Laroche P. 1986: Airborne measurements of electrical atmospheric field produced by convective clouds, Rev. Phys. App., 21, 809-815.

Laroche P., Blanchet P, Delannoy A., Issac F., 2012: Experimental Studies of Lightning Strikes to Aircraft, J. Areospace Lab, 5, AL05-06.

Lawson R.P., J. L. Angus, A. J. Heymsfield, 1998: Cloud Particle Measurements in Thunderstorm Anvils and Possible Weather Threat to Aviation, J. Aircraft, 35, No. 1. 
Leroy D., Coutris P, Fontaine E., Schwarzenboeck A., Lilie L, Korolev A., McFaqhaur Greg, Dezier F., Calmels A., 2016: HAIC/HIWC field campaigns - specific findings on ice crystals characteristic in high ice water content cloud regions, AIAA Aviation, 2016-4056, 12p.

Leroy D., Fontaine E., Scwarzenboeck A, 2016: Ice crystal Sizes in High Ice Water Content Clouds. Part I: On the Computation of Median Mass Diameter from In Situ Measurements, J. Atmos. and Ocea. Tech., 33, 2461-2476.

Leroy D. Fontaine E., Schwarzenboeck A., Strapp J. W., Korolev A., McFaeqhar G., Dupuy R., Gourbeyre C., Lilie L, Protat A., Delanoe F., Dezitter F., Grandin A., 2017 : Ice Crystal Sizes in High Ice Water Content Clouds. Part II: Statistics of Mass Diameter Percentiles in Tropical Convection Observed during the HAIC/HIWC Project, J. Atmos. Ocea. Tech., 34, 117-136.

Leroy D., Lilie L., Weber M., Schwarzenboeck A., Strapp W., 2017: ROBUST hot wire probe efficiency for total water content measurements in glaciated conditions. Geophysical Research Abstracts, vol. 19, EGU2017-13217.

Lilie L., E. Emery, J. W. Strapp, J. Emery, 2005: A Multiwire Hot-Wire Device for Measurement of icing Severity, Total Water Content, Liquid Water Content and Droplet Diameter, $43^{\text {rd }}$, AIAA, Aerospace Sciences Meeting and Exhibit, American Institute of Aeronautics and Astronautics, http://arc.aiaa.org/doi/abs/10.2514/6.2005-859.

Mach D.M. and Koshak W. J., 2007: General Matrix Inversion Technique for the Calibration of Electric Field Sensor Arrays on Aircraft Platforms, J. Atmos. Oceanic Tech, 24, 1576-1587.

Mach D. M., Blakeslee R. J., Bateman M. G., Bailey J. C., 2009: Electric fields, conductivity and estimated currents from aircraft overflights of electrified clouds, J. Geo. Res., 114, D10204, 15p

Mach D. M. 2015: Technique for Reducting the Effects of Nonlinear Terms on Electric Field Measurements of Electric Field Sensor Arrays on Aircraft Platforms, J. Atmos. Oceanic Tech, 32, 993-1003.

MacGorman D. and Rust W. D., 1998: The electrical nature of storms, Oxford University Press, 422p.

Marshall T., Rust W. D., 1991: Electric Field Soundings Through Thunderstorms, J. G. R., 96, 2229722306.

Mason J., 2006: Engine Power Loss in Ice Crystal Conditions, Aero Quaterly, QTR-04, 12-17.

Mazzawy, Robert S., and Strapp J. Walter, 2007: Appendix D - An Interim Icing Envelope: High Ice Crystal Concentrations and Glaciated Conditions. SAE Transactions, Journal of Aerospace, 116, 634-642.

Mazur v., Ruhnke L. H., Rudoplh T., 1987: Effect of E-Field Mill Location on Accuracy of Electric Field Measurements With Instrumented Airplane, J. Geo. Res., 92, 12013-12019.

Merceret F. J., Ward J. G., Mach D. M., Bateman, M. G., Dye J. E., 2008: On the magnitude of the Electric Field near Thunderstorm-Associated Clouds, J. App. Meteorology and Climatology., 47, 240-248. 
Nanevicz J.E., 1974: Recommendations regarding precipitation static noise reduction program on Dassault Falcon 50, SRI Project 3551 Technical Report.

Nanevicz J. E., 1975: Interaction between EMP, Lightning and Static Electricity with Aircraft and Missile Avionics Systems, Agard Lecture Series, №144.

Nicholls, S., J. Leighton, and R. Barker, 1990: A New Fast Response Instrument for Measuring Total Water Content from Aircraft J. Atmos. Oceanic Technol., 7, 706-718.

Noone, K.B., Noone, K.J., Heintzenberg, J., Strom, J., and Ogren, J.A., 1993: In Situ Observations using the Counterflow Virtual Impactor, J. Atmos. Oceanic Technol., Vol. 10, 1993, pp. 294-303.

Papadakis M., Hung K.E., Yeong H. W., 2000: Experimental investigations of water impingement on single and multi-element airfoils, AIAAA, 2000-0100.

Protat A., Bouniol D., Delanoe J., May P. T., Plana-Fattori A., Hasson A., O'Connor E., Gördsdorf U., Heymsfield J., 2009: Assessment of Cloudsat Reflectivity Measurements and Ice Cloud Properties Using Ground-Based and Airborne Cloud Radar Observations, J. Atmos. Ocea. Tech, 26, 17171741.

Protat, A.A., J.J. Delanoë, J.W. Strapp, E.E. Fontaine, D.D. Leroy, A.A. Schwarzenboeck, L.L. Lilie, C.C. Davison, F.F. Dezitter, A.A. Grandin, and M.M. Weber, 2016: The Measured Relationship between Ice Water Content and Cloud Radar Reflectivity in Tropical Convective Clouds. J. Appl. Meteor. Climatol., 55, 1707-1729, doi: 10.1175/JAMC-D-15-0248.1.

Saunders C., 1994: Thunderstorm electrification laboratory experiments and charging mechanisms, J. Geo. Res. A. 99(D5): 10773.

Schiller C., Krämer M, Afchine A., Spelten N., Sitnikov N., 2008: Ice water content of Arctic midlatitude and tropical cirrus, J. G. R, 113, D24208.

Stimmel R. G., Rogers E. , Waterfall F. E., Gunn R., 1943: Part III - Electrification of Aircraft Flying in Precipitation Areas, Proceedings of the I.R.E and Waves and Electrons, 167-177.

Stolzenburg M., Rust W. D., Smull B. F., Marshall T. C., 1998: Electrical structure in thunderstorm convective regions. 1. Mesoscale convective systems, J. G. R., 103, 14059-14079.

Strapp J. W., MacLeod J., Lilie L.E., 2008: Calibration of ice water content in a wind tunnel/engine test cell facility, 15th International Conference on Clouds and Precipitation ICCP-2008, Cancun, Mexico.

Strapp J. W., Lilie L. E., Ratvasky T. P., Davidson C., Dumont C., 2016 : Isokinetic TWC Evaporator Probe : Development of the IKP2 and Performance Testing for the HAIC-HIWC Darwin 2014 and Cayenne 2015 Field Campaigns, $8^{\text {th }}$ AIAA Atmospheric and Space Environments Conference, 2016-4059, 28p.

Strapp, J. W., G. A. Isaac. A. Korolev, T. Ratvasky, R. Potts, P. May, A. Protat, P. Minnis, A. Ackerman, A. Fridlind, J. Haggerty, and J. Riley, 2016: The High Ice Water Content (HIWC) Study of deep convective clouds: Science and technical plan. FAA Rep. DOT/FAA/TC-14/31, available at http://www.tc.faa.gov/its/worldpac/techrpt/tc14-31.pdf. 105 pps. 
Strapp, J. W., Schwarzenboeck, A., Bedka, K. , Bond, T. , Calmels, A. , Delanoë, J., Dezitter, F. , Grzych, M. , Harrah, S. , Korolev, A. , Leroy, D. , Lilie, L., Mason, J., Potts, R. , Protat, A. , Ratvasky, T. , Riley, J., and Wolde, M., 2019. "An Assessment of Cloud Total Water Content and Particle Size from Flight Test Campaign Measurements in High Ice Water Content, Mixed Phase/Ice Crystal Icing Conditions: Primary In-Situ Measurements", FAA Rep. DOT/FAA/TC-18/1, in review and publication process.

Tanner R. L. et al, 1961: Precipitation charging and corona-generated interference in aircraft, Technical Report 73 to the Office of aerospace research, US Air Force Bedford, Massachusetts.

Twohy C. H., Schanot A. J. and Cooper W.A., 1997: Measurement of Condensed Water Content in Liquid and Ice Clouds Using an Airborne Counterflow Virtual Impactor, J. Atmos. Oceanic Tech, 14, 197-202.

Vonnegut B, 1965: Electrical behavior of an airplane in a thunderstorm, Federal Aviation Agency.

Winn W. P., Moore C. B., 1971: Electric field measurements in thunderclouds using instrumented rockets, J. Geophys. Res., 76, 5003-5017.

Winn W. P., 1993: Aircraft Measurement of Electric Field: Self-Calibration, J. Geophysical Res., 98, 7351-7365.

Yost, C. R., Bedka, K. M., Minnis, P., Nguyen, L., Strapp, J. W., Palikonda, R., Khlopenkov, K., Spangenberg, D., Smith Jr., W. L., Protat, A., and Delanoe, J.: A prototype method for diagnosing high ice water content probability using satellite imager data, Atmos. Meas. Tech., 11, 16151637, https://doi.org/10.5194/amt-111615-2018, 2018.

Zöger M., Afchine A., Eicke N., Gerhards M.-T., Klein E., McKenna D. S., Mörschel U., Schmidt U., Tan V., Tuijer F., Woyke T., Schiller C., 1999: Fast in situ stratospheric hygrometers: A new family of balloon-borne and airborne Lyman $\alpha$ photofragment fluorescence hygrometers, J. G. R., 104, 1807-1816.

1807-1816.

